US Army Corps

of Engineers ${ }_{\circledast}$

Engineer Research and

Development Center

Military Engineering Technology Demonstration

\title{
Ice Fog Monitoring Near Fairbanks, AK
}

Dragos A. Vas, Steven E. Peckham, Carl G. Schmitt,

March 2021

Martin Stuefer, Ross G. Burgener, and Telayna E. Wong

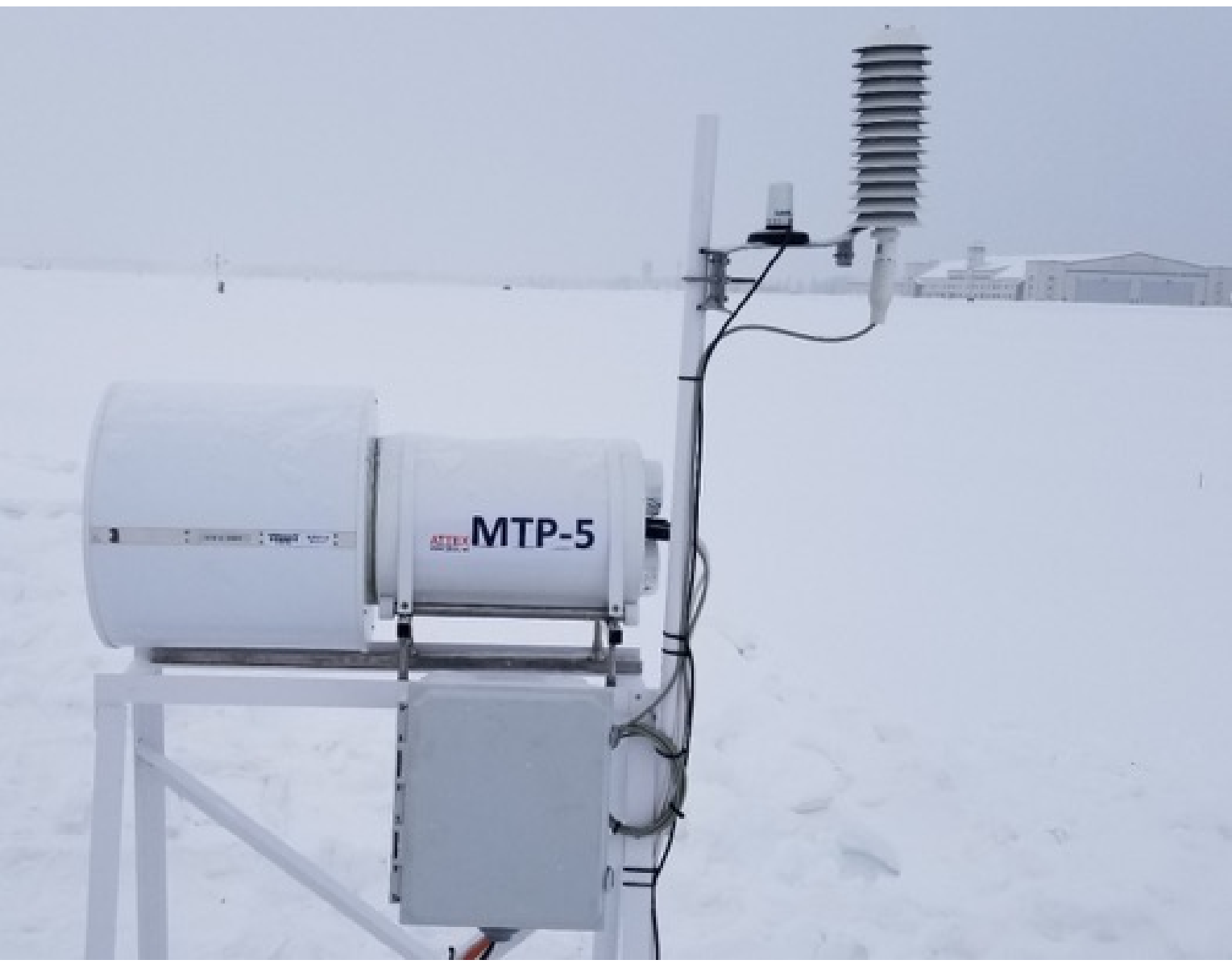


The U.S. Army Engineer Research and Development Center (ERDC) solves the nation's toughest engineering and environmental challenges. ERDC develops innovative solutions in civil and military engineering, geospatial sciences, water resources, and environmental sciences for the Army, the Department of Defense, civilian agencies, and our nation's public good. Find out more at www.erdc.usace.army.mil.

To search for other technical reports published by ERDC, visit the ERDC online library at https://erdclibrary.on.worldcat.org/discovery. 


\section{Ice Fog Monitoring Near Fairbanks, AK}

Dragos A. Vas and Steven E. Peckham

U.S. Army Engineer Research and Development Center (ERDC)

Cold Regions Research and Engineering Laboratory (CRREL)

72 Lyme Road

Hanover, NH 03755-1290

Carl G. Schmitt, Martin Stuefer, Ross G. Burgener, and Telayna E. Wong

University of Alaska Fairbanks

Geophysical Institute

2156 Koyukuk Dr.

Fairbanks, AK 99775

Final Report

Approved for public release; distribution is unlimited.

Prepared for Assistant Secretary of the Army for Acquisitions, Logistics, and Technology 103 Army Pentagon

Washington, DC 20314-1000

Under PE 633734, Project TI1, "Secure and Resilient Power Generation in Cold Regions Environments" 


\section{Abstract}

Ice fog events, which occur during the Arctic winter, result in greatly decreased visibility and can lead to an increase of ice on roadways, aircraft, and airfields. The Fairbanks area is known for ice fog conditions, and previous studies have shown these events to be associated with moisture released from local power generation.

Despite the identified originating mechanism of ice fog, there remains a need to quantify the environmental conditions controlling its origination, intensity, and spatial extent. This investigation focused on developing innovative methods of identifying and characterizing the environmental conditions that lead to ice fog formation near Fort Wainwright, Alaska. Preliminary data collected from December 2019 to March 2020 suggest that ice fog events occurred with temperatures below $-34^{\circ} \mathrm{C}$, up to $74 \%$ of the time ice fog emanated from the power generation facility, and at least $95 \%$ of ice particles during ice fog events were solid droxtals with diameters ranging from 7 to $50 \mu \mathrm{m}$.

This report documents the need for frequent and detailed observations of the meteorological conditions in combination with photographic and ice particle observations. Datasets from these observations capture the environmental complexity and the impacts from energy generation in extremely cold weather conditions.

DISCLAIMER: The contents of this report are not to be used for advertising, publication, or promotional purposes. Citation of trade names does not constitute an official endorsement or approval of the use of such commercial products. All product names and trademarks cited are the property of their respective owners. The findings of this report are not to be construed as an official Department of the Army position unless so designated by other authorized documents. 


\section{Contents}

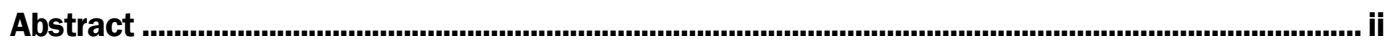

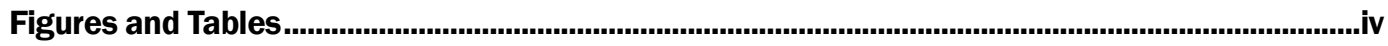

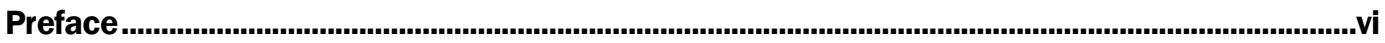

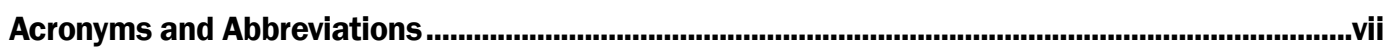

1 Introduction ........................................................................................................................................... 1

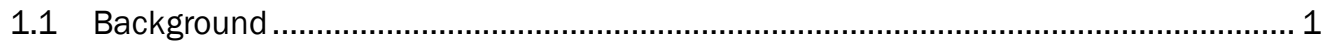

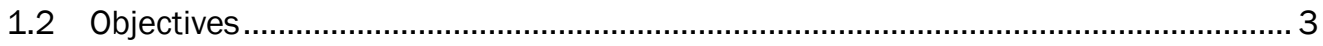

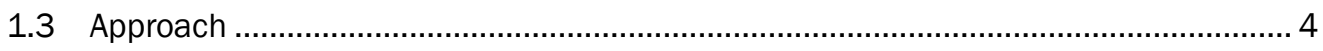

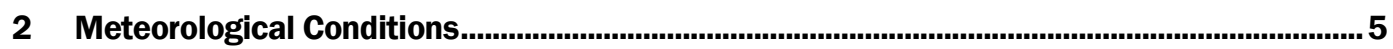

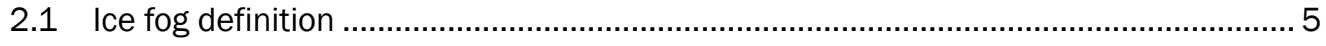

2.2 Overview of synoptic conditions leading to ice fog .............................................. 5

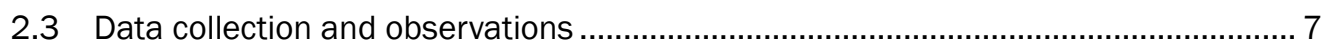

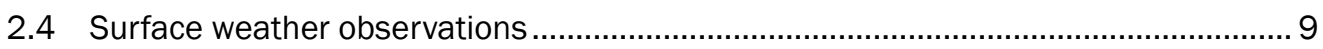

2.5 Vertical weather observations .......................................................................... 16

2.6 Weather observation discussion................................................................ 18

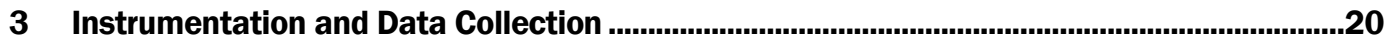

3.1 Instrumentation and field locations................................................................. 20

3.2 Data collection and observations .................................................................... 25

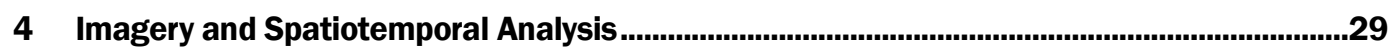

$5 \quad$ Results and Discussion .....................................................................................................31

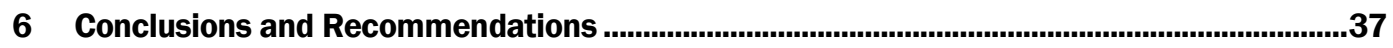

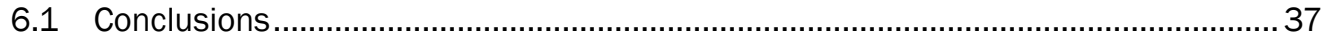

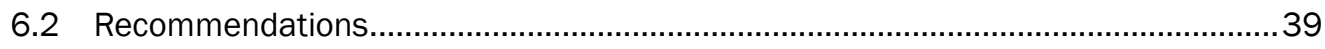

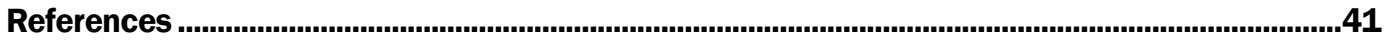

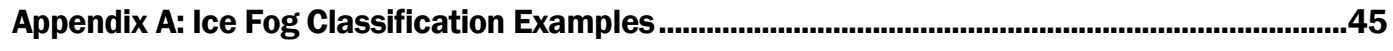

Report Documentation Page ................................................................................................47 


\section{Figures and Tables}

\section{Figures}

1 Top: Time series plots of the 1-hour filtered air temperature (solid line), mean sea-level pressure (dotted line), and horizontal visibility (dashed line) reported by PAFA for 3 December 2016. The colored line at the image base indicates automated station reports of snow and fog (green), haze or mist (orange), or freezing fog (b/ue). Bottom: Hourly filtered cloud layer base elevation for levels $1(-)$, level $2(+)$, and level $3(\mathrm{x})$ reported by PAFA for the same time period, showing the variation in lower cloud cover base elevation in the Fairbanks, Alaska, region

$2 \quad$ Same as Fig. 1 but for 17 to 21 January 2017

$3 \quad$ Same as Fig. 1 but for 10 to 14 January 2019..............................................................15

$4 \quad$ SkewT-LogP diagram showing the radiosonde data collected at PAFA at 1200 UTC on 8 January 2020 between the surface and the $600 \mathrm{mb}$ pressure level.

5 Research area map: The Fort Wainwright main installation is located at the east end of Fairbanks city and $18 \mathrm{~km}$ northwest of the town of North Pole. The directional orientation of the observational instruments and the line of sight are displayed as dotted line arrows

6 Instrumentation field deployment: (a) north-facing Axis camera, (b) eastfacing Axis camera, (c) MTP-5HE, and (d) MTP-5PE

7 Sample panoramas from (a) the north-facing Axis camera and $(b)$ the east-facing Axis camera

8 Microwave temperature profiler MTP-5PE (a) versus Fairbanks International Airport soundings (b) for January 2020

9 Example scattering patterns and size distribution using data collected January and February 2020 from the PPD2K

10 Air temperature at building 4070, 17 December 2019 to 31 March 2020.

The coefficient of determination value between the $2 \mathrm{~m}$ and $10 \mathrm{~m}$ air temperature datasets was 0.9884 , which indicates there is little variation between the two datasets

11 Ice fog records for the (a) east and (b) north panoramic images obtained between 17 December 2019 and 12 January 2020

12 Ice fog records for the (a) east and (b) north panoramas, 13 January 2020 to 31 March 2020

13 Microwave temperature profiler MTP-5HE (a) and MTP-5PE (b) data for 29 February 2020

14 Ice fog event evolution on 29 February: (a) 0541 AKST, (b) 0601 AKST, and (c) 0651 AKST.

\section{Tables}

1 Dates from 2016 to 2019 with low temperatures and calm wind events observed at Fairbanks, Alaska, along with the duration of temperatures below $-35^{\circ} \mathrm{C}$ and minimum horizontal visibility reported with each event. 
These are prime conditions for ice fog events to occur. Events selected for additional examination are in bold...

2 MPT-5HE and MPT-5PE meteorological temperature profiler parameters provided by the manufacturer (RPO ATTEX 2013)

3 Axis Q370 8-PVE specifications provided by the manufacturer (Axis Communications 2020). 


\section{Preface}

This study was conducted for the U.S. Army Engineer Research and Development Center (ERDC), under PE 633734, Project TI1, "Secure and Resilient Power Generation in Cold Regions Environments." The technical monitor was Dr. Thomas A. Douglas (CEERD-RR-RN).

The work was performed by the Terrestrial and Cryospheric Sciences Branch of the Research and Engineering Division, U.S. Army ERDC Cold Regions Research and Engineering Laboratory (CRREL). At the time of publication. Dr. J. W. Weatherly was Branch Chief, and Dr. M. Andrew Niccolai was Acting Division Chief. The Deputy Director of ERDC-CRREL was Mr. David B. Ringelberg, and the Director was Dr. Joseph L. Corriveau.

COL Teresa A. Schlosser was Commander of ERDC, and Dr. David W. Pittman was the Director. 


\section{Acronyms and Abbreviations}

AGL

AKST

ALPACA

ASOS

CCD

CMOS

CRREL

ERDC

MADIS

MSLP

MTP

NOAA

PAEI

PAFA

PAFB

PPD

PPD2K

SBI

UAF

USACE

UTC
Above Ground Level

Alaska Standard Time

Alaskan Layered Pollution and Chemical Analysis

Automated Surface Observing System

Charge-coupled device

Complementary Metal Oxide Semiconductor

Cold Region Research and Engineering Laboratory

Engineer Research and Development Center

Meteorological Assimilation Data Ingest System

Mean Surface Level Pressure

Meteorological Temperature Profiler

National Oceanic and Atmospheric Administration

Eielson Air Force Base

Fairbanks International Airport, Alaska

Fort Wainwright

Particle Phase Discriminator

Particle Phase Detector-200o

Surface-Based Inversion

University of Alaska Fairbanks

U.S. Army Corps of Engineers

Coordinated Universal Time 



\section{Introduction}

\subsection{Background}

Ice fog formation during cold weather events has taken on more significance in the past decade as it influences a broad range of human activities, such as transportation and energy production (Pepin et al. 2009; Bourne et al. 2010; Kim et al. 2014). Ice fog is a cloud that is composed of suspended ice particles, rather than liquid droplets, that is in contact with the ground and that rarely occurs at temperatures greater than $-30^{\circ} \mathrm{C}$ (American Meteorological Society 2012). Ice fog tends to develop near open-water sources, such as rivers and powerplant cooling ponds, and where human activities, such as combustion, yield atmospheric water vapor (Benson 1965; Ohtake 1970; Gultepe et al. 2017). Some events have also been attributed to herds of wildlife exhaling moisture (Benson 1965; Ohtake 1970; Gultepe et al. 2017).

Ice fog can be detrimental to aviation and ground transportation for both civilian and military activities, reduced visibility causing delayed flights and unsafe driving conditions (Walker and Brunner 1982; Gultepe et al. 2014, 2015). According to Gultepe et al. (2014), ice fog is also related to frost formation, which could lead to deposition of ice on aircraft, runways, and infrastructure such as roads and power lines. Gultepe et al. (2019) and Gultepe and Heymsfield (2016) suggest that accidents related to weather and low-visibility conditions over the Arctic regions could increase tenfold because of increasing air traffic. In addition, the large number and characteristics of ice particles during ice fog events and their impact on the surface energy balance is not well understood. It must be explored further and applied to global weather and climate models (e.g., Girard and Blanchet 2001a, 2001b). Therefore, ice fog conditions can have major impacts on human activity (aviation, transportation, energy transmission) and on Earth's climate.

Power plants contribute to ice fog formation through the release of humid stack gases (Porteous and Wallis 1970) and via water vapor from cooling ponds (Walker and Brunner 1982). Observational data collected and provided in the Fairbanks North Star Borough report by Walker and Brunner (1982), and other reports by researchers from the U.S. Army Engineer Research and Development Center's Cold Region Research and Engineering 
Laboratory (ERDC-CRREL), implicated the Fort Wainwright cooling pond as a contributing factor to the significantly reduced visibility that caused many winter accidents on the adjacent Richardson Highway. While the study by Walker and Brunner (1982) focused on identifying potential ice fog suppression methods for the Fort Wainwright power plant cooling pond, their findings indicate that the Richardson Highway near Fort Wainwright experienced periods of horizontal visibility less than $215 \mathrm{~m}$ and ice buildup on the road surface during ice fog events. The power plant on Fort Wainwright switched from water cooling to an air-cooled condenser in 2007 due to the significant adverse impacts the cooling-pond-generated ice fog had on local transportation. Nevertheless, ice fog generated by the Fort Wainwright power plant moisture plume is still a major concern to local ground and air traffic. For example, Ladd Army Airfield is located $1400 \mathrm{~m}$ north of the power plant, and aircraft departing from and arriving at the Ladd Army Airfield could potentially face icing issues under certain weather conditions.

Enhanced understanding of power generation plumes in extremely cold environments along with accurate environmental forecasting could greatly improve aviation and ground transportation safety. Near power generation facilities, the plume could reach high enough and the inversion be strong enough for adequately warm air to exist aloft. Water droplets or a mix of ice and water particles could simultaneously exist in these warm, elevated plumes, leading to icing conditions for aircraft. Theoretically, in such a cold environment, this mixed-phase plume would eventually transition to consisting wholly of ice particles along the plume pathway.

Studies have found several mechanisms that contribute to ice fog. Wexler $(1936,1941)$ explained the extremely low surface temperatures by examining thermal radiative cooling. The amount of cooling at the surface is limited by downwelling longwave radiation from an overlying layer with higher temperatures. The radiative cooling at the surface leads to a decreased saturation vapor pressure, resulting in fog formation. Bowling et al. (1968) expanded our understanding by demonstrating that ice fog events in Alaska may be related to regional and larger-scale meteorological processes. The investigation findings revealing that conditions favorable for ice fog formation in the Interior Alaska region often develop when a cold high-pressure region is advected from Siberia, resulting in a broad anticyclonic circulation with weak surface winds; and the associated subsidence warms the air above an initial surface cold dome. Benson (1965) 
and Gotaas and Benson (1965), in their studies of ice fog events, suggest ice fog near urban areas is primarily a human-caused phenomenon in which water vapor is released into an extremely cold and dry surface layer and is subsequently trapped by weak winds and a strong overlying temperature inversion.

The challenge, given the remaining need to fully understand extreme cold weather events and their impact on civilian and military activities, is in part due to limited surface in situ and remote-sensing observations (Gultepe et al. 2015; Gultepe and Heymsfield 2016). Specifically, a need exists to have high-resolution spatiotemporal observations of environmental factors associated with ice fog. These observations should be made not only at the surface but also aloft to develop an understanding of the microscale urban environment weather and terrain associated with the adverse environmental conditions. For example, there needs to be observations made with high enough fidelity to explain the evolution of power plant plumes and how these plumes enhance ice fog formation. This understanding can lead to advances in numerical weather prediction models, enabling them to forecast these events farther in advance. This would give decision makers sufficient situational awareness to permit responsive actions, such as preparation of roadways, modification of energy production methods, or relocation of personnel and equipment. To address these requirements, CRREL, in collaboration with University of Alaska Fairbanks (UAF), installed an observational network at Fort Wainwright, Alaska. This report will discuss the network and its ability to observe adverse weather conditions near Fort Wainwright.

\subsection{Objectives}

Many questions remain regarding ice fog formation near Fort Wainwright and in the vicinity of Fairbanks, Alaska. Therefore, this study addressed the following:

- Where do ice fog conditions develop near Fort Wainwright and how do the ice fog conditions evolve in time?

- Does a correlation exist between the current Fort Wainwright power production system and the location or severity of ice fog events?

- What role does the low-level temperature profile (e.g., between the surface and $300 \mathrm{~m}$ above ground level [AGL]) play in the formation of ice fog near Fort Wainwright? 
- How does the vertical temperature and wind profile affect particle shape and concentration near power plant moisture plumes?

- Can numerical models simulate the power plant moisture plume emissions and dispersion given the extreme cold and semi-permanent nocturnal environment?

This report documents the efforts undertaken the winter of 2019 to address these deficiencies and the findings from these efforts.

\subsection{Approach}

This report discusses the network of local weather observations and additional instrumentation being installed around Fort Wainwright and the Fairbanks, Alaska, region. The purpose of installing the equipment is to collect data during the cold season, starting December 2019. This effort brought together investigators from ERDC and UAF under a coordinated project to complete the installation in a timely manner. Ultimately, this set of fielded equipment will collect a core set of observations designed to answer the questions above regarding the timing and location of ice fog formation on Fort Wainwright. 


\section{Meteorological Conditions}

\subsection{Ice fog definition}

The meteorological community defines ice fog as a surface-contacting cloud composed of suspended ice particles and ice crystals, primarily droxtals, ranging in size from 12 to $100 \mu \mathrm{m}^{*}$ in diameter, that rarely occurs at temperatures greater than $-30^{\circ} \mathrm{C}$ (American Meteorological Society 2012). Gultepe et al. (2014) suggest ice fog particles develop by deposition nucleation in saturated, based on relative humidity with respect to ice, air masses. The small particle size and extremely low temperatures distinguish ice fog from other ice particles typically observed during the Arctic winter season, such as diamond dust, which ranges in size from 20 to $200 \mu \mathrm{m}$ but often is larger than $100 \mu \mathrm{m}$ in diameter. These larger particles have fall speeds and a size range to provide the appearance of light precipitation to an observer. Further, optically, diamond dust generates observable phenomena such as sun dogs and light pillars while ice fog produces a uniform haze.

Differentiating between ice fog and diamond dust based solely on particle size (i.e., particles between 20 and $100 \mu \mathrm{m}$ in diameter) could be subjective given the similarity in definition (Gultepe 2014). Schmitt et al. (2013) conducted a series of observations in Fairbanks to gather information to clarify particle types in extremely cold environments. Schmidt et al. (2013) observed two distinct populations of atmospheric ice crystals in the Fairbanks region during extremely cold winter events: diamond dust and ice fog. Diamond dust crystals were generally large (20 to $200 \mu \mathrm{m}$ ) plateshaped crystals with some irregularities and aggregates. Ice fog particles were relatively small $(<30 \mu \mathrm{m})$, quasi-spherical (droxtal) particles that occurred only in the presence of a very strong near-surface temperature inversion. Thus, ice fog has a distinct, identifiable size and structural difference from other ice particles observed in the Fairbanks region.

\subsection{Overview of synoptic conditions leading to ice fog}

The Fairbanks area is prone to ice fog formation because the region often experiences optimal environmental conditions for its development

* For a full list of the spelled-out forms of the units of measure used in this document, please refer to U.S. Government Publishing Office Style Manual, 31st ed. (Washington, DC: U.S Government Publishing Office, 2016), 248-252, https://www.govinfo.gov/content/pkg/GP0-STYLEMANUAL-2016/pdf/GPO-STYLEMANUAL-2016.pdf. 
(Benson 1970; Mayfield and Fochesatto 2013; Hartmann and Wendler 2005; Tran and Molders 2015). These conditions include (1) ambient temperatures lower than $-30^{\circ} \mathrm{C}$ with weak winds in the lowest $500 \mathrm{~m}$, which is contained by the surrounding terrain; (2) a strong near-surface temperature inversion that inhibits vertical turbulent mixing; (3) significant emission of water vapor near the base of the inversion; and (4) the presence of inactivated aerosol particles to serve as ice nuclei. The first two are related to the local meteorological conditions often observed during the semi-permanent nocturnal conditions in the Alaska Interior winter season. Shulski and Wendler (2007) found the climatological mean January temperature in Fairbanks to be approximately $-21^{\circ} \mathrm{C}$ with an average of at least 5 days with the minimum temperature lower than $-40^{\circ} \mathrm{C}$ and a mean occurrence of 10 days with ambient temperatures at or below $-40^{\circ} \mathrm{C}$.

During the winter months, radiative cooling produces a strong surface inversion as polar anticyclones build into the region and radiative cooling lowers the surface temperature during the polar night. In addition, weak horizontal pressure gradients and significant topographic features support extended periods with weak near-surface winds. Temperature inversions in the vicinity of Fairbanks are strong and persistent such that the vertical temperature gradient at times reaches $30^{\circ} \mathrm{C}$ per $100 \mathrm{~m}$ from the surface to 50-100 m AGL (Bilello 1966; Malingowski et al. 2014). The temperature inversion is sufficiently strong that katabatic flow from the surrounding Yukon-Tanana Uplands is not capable of scouring the cold, dense air; and instead the relatively warm air flows over the low-lying air pool in the Tanana and Chena River valleys in which Fairbanks is situated. Hence, the surface is decoupled from the synoptic weather patterns above; and emissions from anthropogenic activity remain trapped in the region, leading to intensification of the air pollution.

Benson (1965) and Bowling et al. (1968) identified three phases of synoptic-scale weather patterns with ice fog events in the Fairbanks, Alaska, region. In a study similar to Bowling et al. (1968), but failing to recognize these previous published findings, Turner et al. (2013) presented three synoptic-scale weather pattern phases. They separated these weather pattern phases into three distinct identifiable events as follows. Prior to the occurrence of ice fog (preliminary phase), unsettled weather exists with a period of cloud cover, snow showers, and relatively low surface pressure. As a high-pressure system builds into the Alaskan Interior, the observed surface pressure at Fairbanks rises, and the cloud cover decreases. During 
this transition, the observed wind becomes calm, leading to a period of uninterrupted radiative cooling and, sometimes quite rapidly, falling surface temperatures. The amount of cooling is modulated by a variety of local phenomena (e.g., terrain) or weather (e.g., cloud formation) (Wexler 1936, 1941; Bradley et al. 1992; Curry et al. 1996; Pepin et al. 2009; Gultepe et al. 2014).

As the event matures to the main phase, surface temperatures fall below $-35^{\circ} \mathrm{C}$ and remain almost constant or decrease slowly. About $300 \mathrm{~m}$ above the surface, the air temperature increases due to warm air advection, producing a strong surface-based temperature inversion. Despite the environment being effectively desiccated, power plants, automobiles, and sections of open river water are localized sources of surface moisture within the Fairbanks region. At the surface-level, the absolute humidity is increased near these sources, leading to supersaturation with respect to ice at higher temperatures; and ice fog forms either through condensation on particulates or through homogeneous nucleation, reducing surface visibilities. Over time, clouds expand under the surface inversion, with the top of the cloud layer at the top of the surface-based inversion.

The recovery phase begins when an approaching cyclone brings clouds to the region and warm air advection increases the air temperature aloft, subsequently lowering and sharpening the original inversion. With the strong inversion, diabatic processes (including latent heat release), a net downward radiative heat flux, and turbulent mixing erode and warm the surface-based inversion layer, leading to the elimination of ice fog. The temperature inversion is not always broken in the recovery phase, but the low surface temperatures supporting ice fog formation cease.

\subsection{Data collection and observations}

The National Oceanic and Atmospheric Administration (NOAA) provides an archive of automated weather observations from around the world under the Meteorological Assimilation Data Ingest System (MADIS). These observations originate from various platforms but are typically generated by an automated surface observations system. The MADIS archive provides the research community an as-is collection of historical observations with few quality control adjustments so that the information provided is as close as possible to original reports. This study obtained MADIS-provided surface weather observations for Fairbanks International Airport, Alaska (hereafter referred to by the International Civil Aviation Organization 
identification code PAFA); Fort Wainwright (PAFB hereafter); and Eielson Air Force Base (PAEI hereafter) for the cold season (December through March) for 2015 to 2019. In their original form, these observations were generated at irregular time intervals, so the data was filtered to an hourly time interval before investigating for time periods when the meteorological conditions supported ice fog formation.

A cursory examination of the identified low temperature and calm wind events observed at Fairbanks reveals that several events occur each year. These events last several hours to several days, and the greatest reduction in visibility is often associated with longer events.

To identify events at PAFA with the greatest probability of ice fog formation, the criteria of an observed air temperature below $-35^{\circ} \mathrm{C}$, rather than the American Meteorological Society $-30^{\circ} \mathrm{C}$ threshold, and calm winds (below $1 \mathrm{~m} / \mathrm{s}$ ) were used in this study after finding these criteria better isolated dates in which ice fog events most likely occurred near Fairbanks. Further, this study emphasizes events occurring between 1 December and 12 January as these days have the least impact from shortwave insolation (Bowling et al. 1968). The filtering analysis identified several periods in which ice fog could have occurred over four winter seasons (Table 1).

Table 1. Dates from 2016 to 2019 with low temperatures and calm wind events observed at

Fairbanks, Alaska, along with the duration of temperatures below $-35^{\circ} \mathrm{C}$ and minimum horizontal visibility reported with each event. These are prime conditions for ice fog events to occur. Events selected for additional examination are in bold.

\begin{tabular}{|l|c|c|}
\hline \multicolumn{1}{|c|}{ Dates } & $\begin{array}{c}\text { Duration } \\
\text { (hours) }\end{array}$ & $\begin{array}{c}\text { Min. Visibility } \\
\text { (km) }\end{array}$ \\
\hline 11-12 Jan 2019 & 43 & 1.6 \\
\hline 5-8 Jan 2019 & 81 & 2 \\
\hline 29 Jan 2018 & 6 & 2 \\
\hline 26 Jan 2018 & 16 & 2 \\
\hline 6-9 Mar 2017 & 27 & 16 \\
\hline 2-3 Mar 2017 & 9 & 16 \\
\hline 11-12 Feb 2017 & 30 & 4.8 \\
\hline 22-23 Jan 2017 & 32 & 9.6 \\
\hline 15-20 Jan 2017 & 43 & 0.4 \\
\hline 7 Dec 2016 & 1 & 16 \\
\hline 4-5 Dec 2016 & 25 & 9 \\
\hline
\end{tabular}


Unfortunately, one event (5-8 January 2019) was removed from consideration as several soundings from PAFA were unavailable from the open archives. The remaining periods of interest were then selectively reduced to several key events: 4-5 December 2016, 15-20 January 2017, and 11-12 January 2019. These had observed surface temperatures and surface wind speeds that meet the ice fog event criteria, horizontal visibility reduced to as low as $1.6 \mathrm{~km}$, and fog reported in the vicinity. The following section presents the analysis of surface weather observations from these events.

\subsection{Surface weather observations}

The team generated time series plots of the air temperature, mean surface level pressure (MSLP; hectopascals), horizontal visibility (meters), and the reported current weather at PAFA for three events of interest to identify occurrences of ice fog. The event phase classification is supported through plots of the cloud layer base elevation (meters) observed at PAFA. Observations from PAFA reveal that light snow was falling on 3-4 December 2016 up to 2300 UTC (coordinated universal time) on 4 December and that the reported reduction in horizontal visibility at PAFA correlates with the ending of snowfall (Figure 1). Not shown in the figure are the reports of snow showers ending nearby at PAFB after 2200 UTC on 3 December and at PAEI at 2100 UTC on 4 December. These differences in the end of precipitation are too varied explain by synoptic system propagation and suggest that local forcing or mesoscale circulations modulated the precipitation process across the Fairbanks region.

Following ice fog event phase nomenclature of Benson (1965) and Bowling et al. (1968), the preliminary phase of the first ice fog event began around oooo UTC on 3 December 2016 as warm moist air advection occurred above the low-level inversion. After this, the surface environment began to cool; and light precipitation fell. The reports of precipitation at PAFA show that it occurred simultaneously with the cooling surface temperatures. The relatively low surface pressure increased over time, and observed winds became calm. However, the low-level clouds and lower cloud bases remained throughout this transition. Rapid decreases in the surface temperature, caused by radiative cooling, developed within 12 hours, the temperature dropped nearly $15^{\circ} \mathrm{C}$ over the next 24 hours. 
Figure 1. Top: Time series plots of the 1-hour filtered air temperature (solid line), mean sea-level pressure (dotted line), and horizontal visibility (dashed line) reported by PAFA for 3 December 2016. The colored line at the image base indicates automated station reports of snow and fog (green), haze or mist (orange), or freezing fog (blue). Bottom. Hourly filtered cloud layer base elevation for levels $1(-)$, level $2(+)$, and level $3(x)$ reported by PAFA for the same time period, showing the variation in lower cloud cover base elevation in the Fairbanks, Alaska, region.
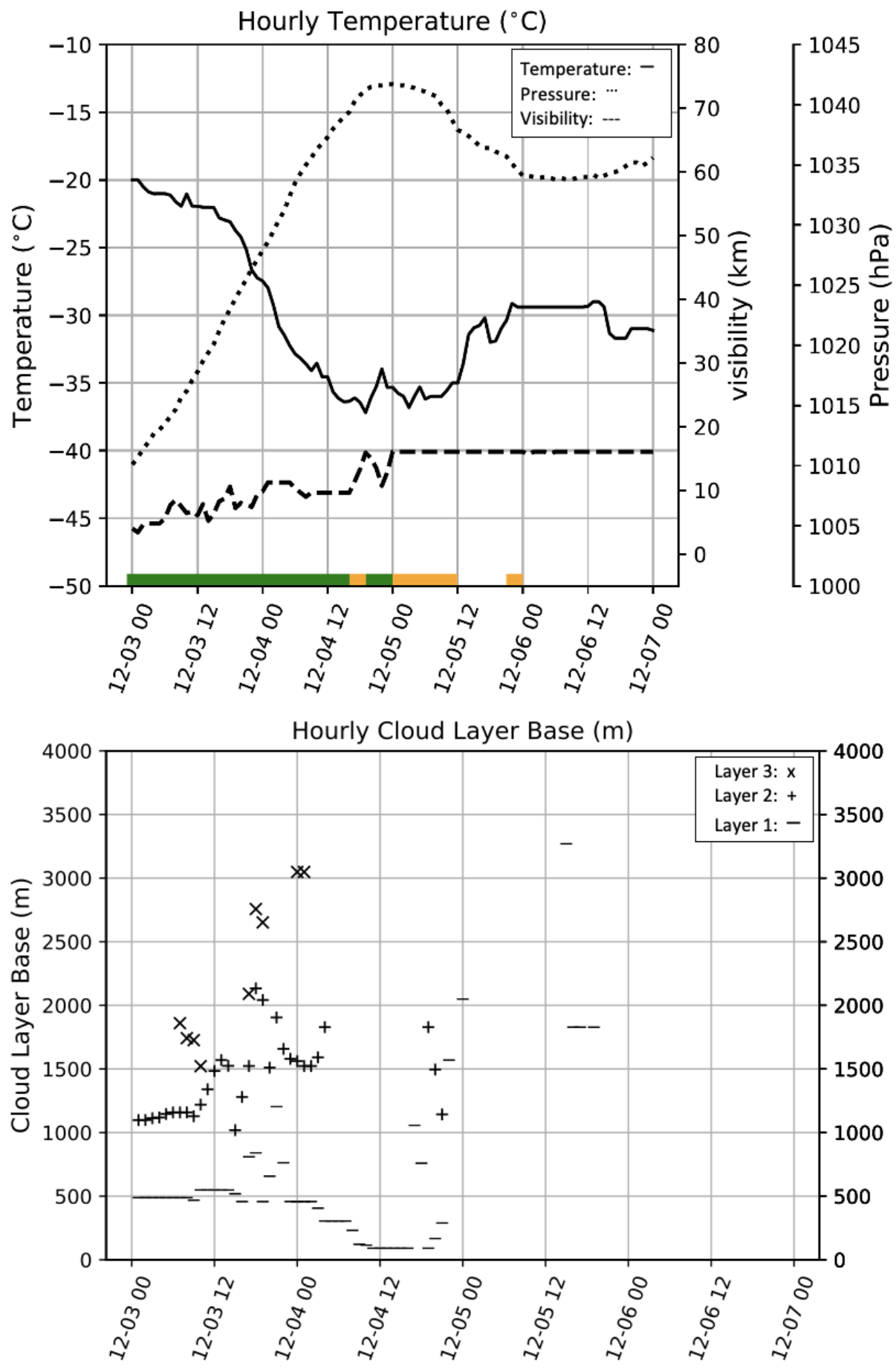
The main phase began around oooo UTC on 4 December as temperatures remained nearly constant. At this time, reports of ice fog and low visibility are assumed to occur when haze and reduced horizontal visibility dominate the observation reports. Later in the period, there were reports of patchy fog conditions at PAFA between oooo UTC until 1120 UTC on 5 December 2016, with a single cloud base below $500 \mathrm{~m}$. And nearby, PAFB reported haze with no overlying clouds from about 2200 UTC on 3 December to about 0900 UTC on 5 December 2016, with visibility reduced at times to below $5 \mathrm{~km}$. This haze persisted until o80o UTC on 5 December. Then clear skies were observed as surface winds increased to between 1.5 and $3 \mathrm{~m} / \mathrm{s}$ and the reduced visibility concluded.

An undulation in the observed temperatures occurred around 2100 UTC on 4 December 2016 at the same time the cloud layer base between 1 and $2 \mathrm{~km}$ and light snow were reported at PAFA. An interesting feature is that the cloud layer base was close to the ground at 1200 UTC on the 4 th, but this low cloud deck broke up around 1800 UTC and temperatures increased for several hours. This behavior suggests that subsynoptic-scale forcing induced light precipitation and that the associated turbulent mixing disrupted the radiative cooling under the shallow inversion layer, which resulted in warmer temperatures and a higher cloud layer base.

Surface air temperatures began to recover from their lowest values with an approaching region of low pressure around oooo UTC 5 December 2016. There were reports of clouds at times between 1400 and 1600 UTC, but otherwise the sky remained cloud free. MSLP lowered approximately $10 \mathrm{hPa}$ over the next day, and visibility was reported to be $16 \mathrm{~km}$ or greater. All of these are indicative of the recovery phase.

The second event exhibited what might be considered typical ice fog event behavior as during the preliminary phase there was relatively low surface pressure, which rises; a cloud layer base, which lowers over time; and calming of the winds. Prior to 1200 UTC on 18 January 2017, PAFA, PAFB, and PAEI all reported light snow with occasional periods of mist as the air temperature cooled (Figure 2).

Between 0800 UTC on 18 January and 0300 UTC on 19 January 2017, the event main phase, the air temperature remained nearly constant at or below $-43^{\circ} \mathrm{C}$. Likewise, the MSLP was nearly constant at a relatively high value of approximately $1004 \mathrm{hPa}$. Freezing fog was reported at PAFA with 
horizontal visibility less than $10 \mathrm{~km}$. There was some uniformity along the Chena and Tanana river valleys as short periods of dense fog were also reported at PAFB and PAEI between 1800 and 2300 UTC on 18 January 2017 with horizontal visibility occasionally as low as 400 to $800 \mathrm{~m}$.

Figure 2. Same as Fig. 1 but for 17 to 21 January 2017.
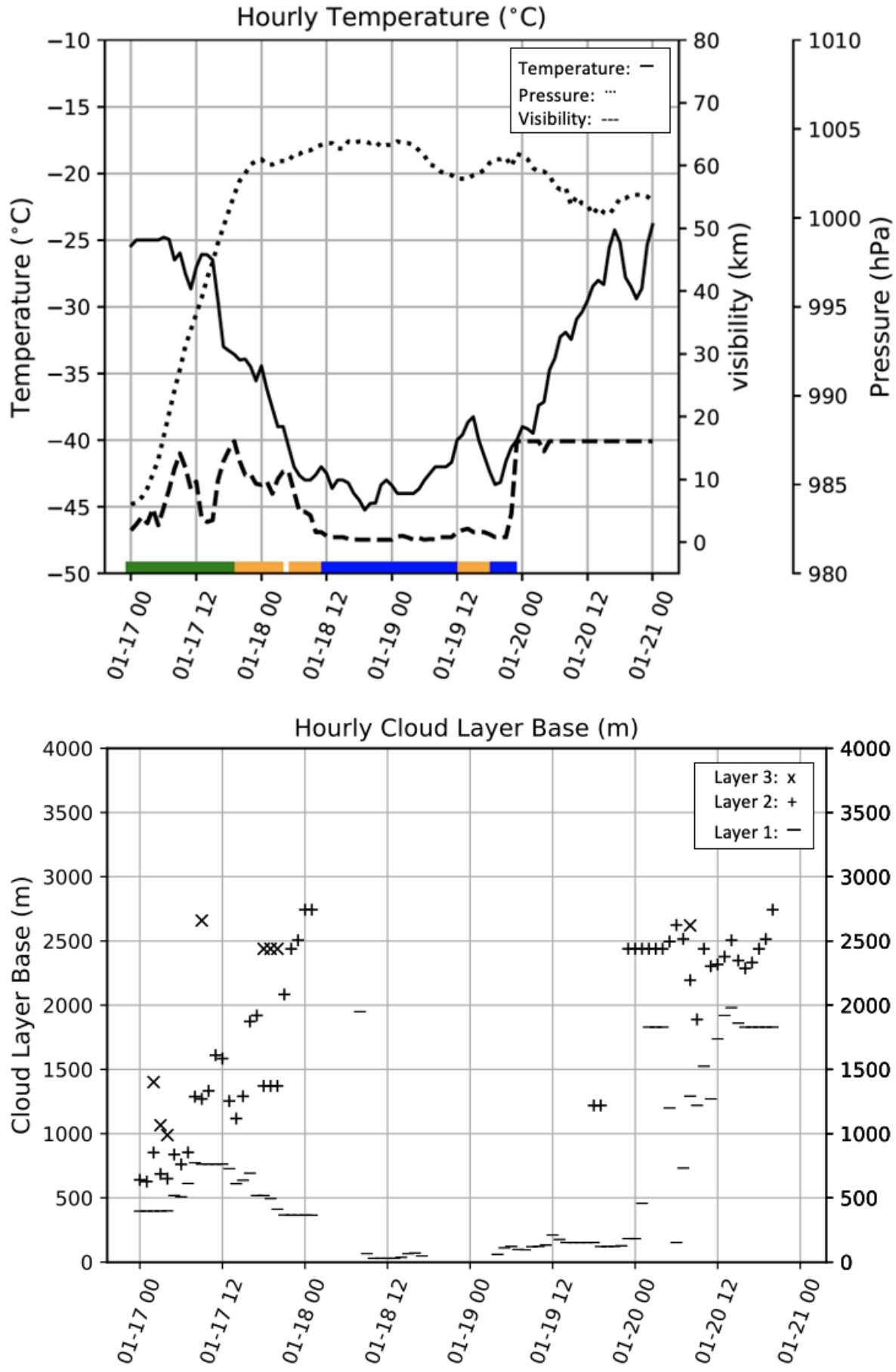
On 19 January 2017, there was a break in the reporting of freezing fog between 1200 and 1800 UTC, and there was a small jump in the cloud layer base even though it remained near the ground. Surface pressure dropped slowly for about 9 hours as the observed surface temperatures increased, followed by a 4-hour period where the MSLP increased and air temperatures rapidly fell $5^{\circ} \mathrm{C}$. The cloud layer bases were reported at different elevations between the three sites, suggesting mesoscale features were again influencing the ice fog episode. After 1400 UTC, the surface temperatures decreased at PAFA and at the neighboring observation stations, the MSLP increased, and the cloud layer base lowered before slowly lifting throughout the next day. Light snow was reported at PAEI as well. The overall behavior was consistent with a typical ice fog event in which the inversion lifts with time, coincident with warming surface temperatures, followed by increased elevation of the cloud layer base. And while typical in behavior, this event did appear to occur over 36 hours, making it most likely one of the more significant reported ice fog events for the Fairbanks area in the 2010s. Further, the rise and fall of the temperature and pressure over several hours coincided with fluctuations in the cloud layer base, suggesting the existence of a mesoscale phenomenon, such as a seiche or gravity waves (Benson 1965; Chemel et al. 2009), modulating the ice fog event in the Fairbanks region. The exact cause remains to be investigated.

The recovery phase appears to have occurred by oooo UTC on 20 January 2017. After the ice fog event, starting around 1200 UTC on 19 January, a short period of mist was observed at the different observation sites until 0500 UTC on 20 January 2017. After this time, which is associated with the recovery phase, the cloud layer base increased and became variable with height. Surface air temperatures continued to rise, and there were no longer reports of ice fog in the Fairbanks region as visibility became unlimited and cloud bases were above $1500 \mathrm{~m}$.

The third event examined began on 12 January 2019. The surface began to cool and light precipitation fell around oooo UTC (Figure 3). Reports of precipitation continued through the period as the surface temperatures became extremely cold. Snow was reported at PAFB until 1900 UTC on 11 January, then there were periods of haze or mist until o80o UTC on 12 January. Likewise, PAEI last reported light snow at 1811 UTC on 11 January and then haze from 0400 on 12 January until 1556 UTC. The surface pressure climbed over time, the cloud cover decreased, and the observed wind became calm (not shown). 
After 0000 UTC on 12 January 2019, the surface temperatures remained almost constant or decreased slowly, which is typical for the main phase of an ice fog event. However, the surface pressure continued to increase slowly to its peak reading near 1200 UTC. Regarding clouds and precipitation, the behavior was typical for ice fog events in that snow and fog with multiple layers of clouds were observed on 12 January 2019 and that the cloud bases showed lowering and unification into a single shallow cloud layer. Snowfall and reduced visibility were reported until 1945 on 12 January, followed by mist and reduced visibility, which continued for nearly another 24 hours. At PAFB, periods of haze and visibility reduced to distances of $1.4 \mathrm{~km}$ or less were observed until 2223 on 12 January, but the overall duration of significantly reduced horizontal visibility was just a few hours centered around 1200 UTC. The event had a similar intensity and evolution at PAEI where mist was reported after 1600 UTC on 12 January, and it continued until 1923 UTC on 12 January when warming air temperatures and clear conditions developed.

At approximately 2200 UTC on 12 January 2019, the observed weather implied the beginning of the recovery phase as higher cloud layer bases were observed, MSLP values decreased, and low-level winds increased. The observed temperatures during this event deviated from the expected behavior, with the coldest values reported on 12 January 2019. Again, the study assumed that reports of haze and reduced visibility with this event were instead observations of ice fog and reduced horizontal visibility. And in this case, the ice fog development appeared to depend on mesoscale forcing and local moisture emissions as the region between PAFA, PAFB, and PAEI experienced ice fog with reduced horizontal visibility at different times instead of uniformly.

In summary, the timeseries plots of PAFA surface observations for all of the examined events showed a similar pattern where the lowest temperatures occurred near the period with the highest observed MSLP. In addition, there was a pattern of light snow followed by weather events that apparently should have been recorded as light to moderate ice fog conditions as the temperatures fell below $-35^{\circ} \mathrm{C}$. Instead, when the observed horizontal visibility was reduced during the lowest temperatures, there were reports of haze, mist, or frozen precipitation. The hourly reports at PAFA for the same time periods reveal a tendency of cloud layer bases to lower and dissipate simultaneously with the reported horizontal visibility reduction. These behaviors align with the previously published accounts of ice 
fog events for Fairbanks, Alaska, and are a strong indication that all events should have ice fog mentioned in the surface observation records.

Figure 3. Same as Fig. 1 but for 10 to 14 January 2019.
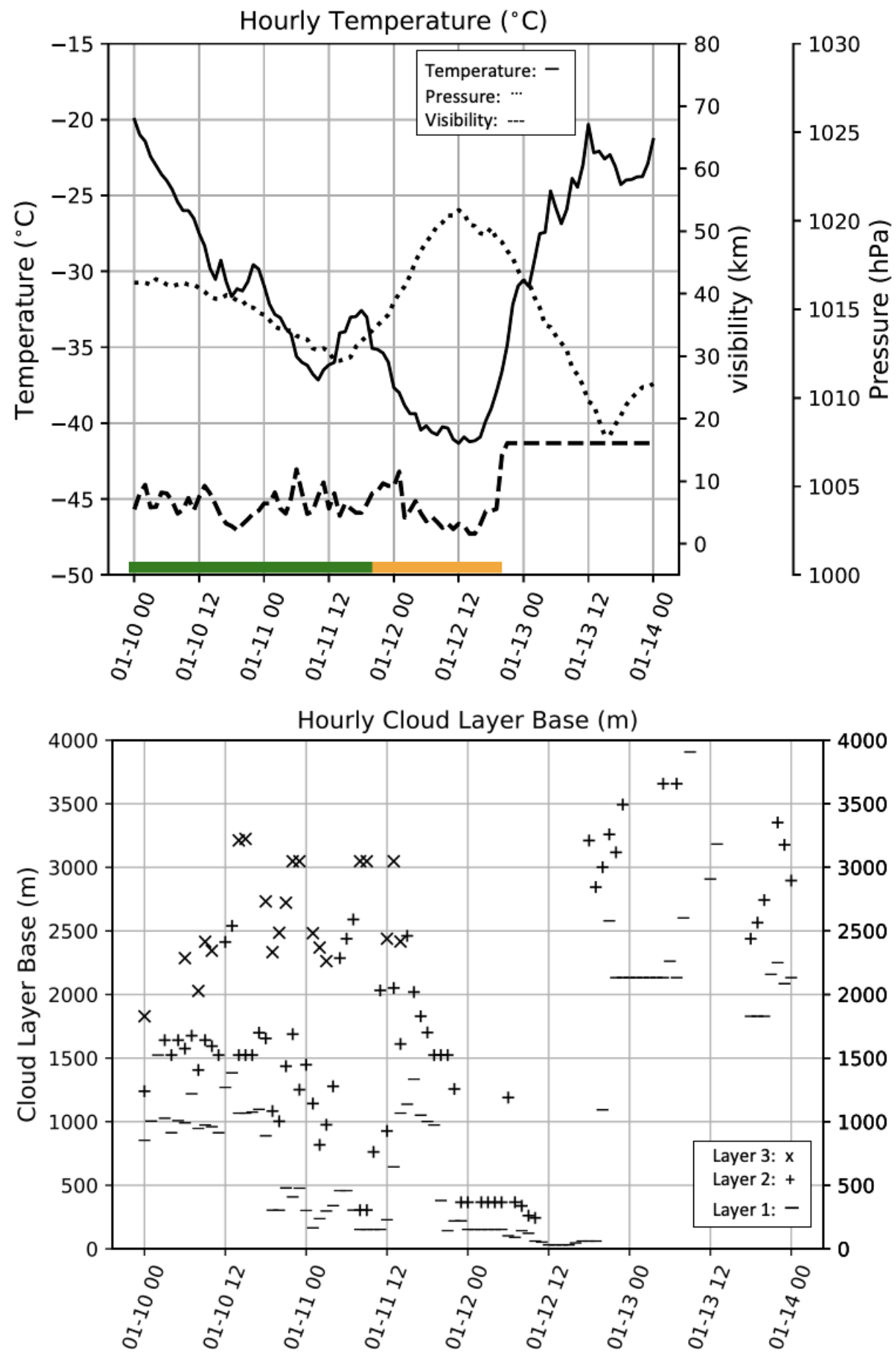

This failure to obtain an expected ice fog report during extremely cold conditions leads to a need to explain how the Automated Surface Observing 
System (ASOS) algorithm records obscurations. When dewpoint is missing or unreliable due to very low humidity, the ASOS algorithm defaults to one of a set of possible answers where the response is determined through a conditional test. The algorithm reports haze for visibilities between 4 and 7 miles ( 6.4 and $11.3 \mathrm{~km}$ ), mist for visibilities between 4 miles and $5 / 8$ mile (6.4 and $1 \mathrm{~km}$ ), and freezing fog (fog that produces a coating of rime or glaze on exposed surfaces) for visibilities below $5 / 8$ mile $(1 \mathrm{~km})$ (NOAA et al. 1998). Curiously, these weather conditions are more appropriate for warmer weather (e.g., $-10^{\circ} \mathrm{C}$ to $-20^{\circ} \mathrm{C}$ ) as there is an assumption of mixed-phase particles instead of only ice particles existing under extremely low temperatures. Therefore, the ASOS visibility-based weather report algorithm does not provide an accurate particle description and requires a researcher to assume that ice fog exists during periods of reduced visibility and extremely low temperatures.

\subsection{Vertical weather observations}

Surface-based inversions (SBIs), defined as an increasing temperature with height, are a well-studied phenomenon. Many modeling and observational studies have been conducted over the past century (e.g., Wexler 1936, 1941; Stull 1988; Bradley et al. 1992). SBI formation is caused by radiational cooling above a snow-covered surface that starts near the surface and spreads upwards (e.g., Malingowski et al. 2014). Through radiative cooling, a strong surface-based temperature inversion develops with the temperature gradient and height of the SBI being a function of several environmental factors, including low-level clouds and moisture, wind profile, longwave-radiation divergence, and topography. The SBI elevation is defined as the height above the surface at which the temperature gradient changes from being positive upward to negative upward. SBI heights are typically about 300 to $500 \mathrm{~m}$ AGL but have been reported as high as 700 m AGL (Hartmann and Wendler 2005; Kahl et al. 1992; Tran and Molders 2011; Mayfield and Fochesatto 2013; Malingowski et al. 2014).

The SBI can be very strong under calm anticyclonic conditions and when the thermal radiation divergence is sufficiently large enough that the only way the SBI can be broken is through a change in synoptic conditions (Pepin et al. 2009). And while the pool of cold air associated with the SBI is transient, its formation and destruction are controlled by synoptic conditions (atmospheric winds and radiation balance) as well as the interaction with local topography (e.g., Busch et al. 1982; Kahl et al. 1992; Pepin et al. 2009). This often occurs when strong synoptic-scale winds cause 
large-scale horizontal advection of warm, relatively moist air, which can overflow and dissipate the SBI by increasing longwave downwelling radiation and the downward mixing of warmer air (Stull 1988).

The structure of the SBI is important for understanding ice particles in the Fairbanks region and across the Arctic. The reason is that the temperature and humidity above the surface strongly influence the structure of ice particles. The higher temperatures and higher humidity several hundred meters above the surface can aid in the production of larger particles or different structures (e.g., diamond dust), which settle and increase the humidity near the surface. Hence, observations need to be made not only of the temperature and humidity at the surface but also for the lower parts of the troposphere to gain a full understanding of the temperature and humidity profile and its evolution during ice fog events.

The release of radiosondes is the common method used to gather data to examine the vertical structure of the atmosphere's physical properties (temperature, pressure, humidity, horizontal winds, etc.). For the Fairbanks region, radiosondes are released from PAFA daily at 0000 and 1200 UTC. The data from the soundings, in this case obtained from the University of Wyoming (2019), are often plotted on thermodynamic diagrams such as the SkewT-LogP diagram (Figure 4). The thermodynamic diagram displays the air temperature (black line), the dewpoint temperature (blue line), and wind speed and direction (barbs) at various pressure levels above the observation site. These diagrams are useful for quantifying the depth and intensity of SBIs and for identifying layers of clouds or the warming and cooling of air above the surface by advection (wind transport). Sources outside of this report provide further information regarding the analysis and interpretation of data using thermodynamic diagrams. 
Figure 4. SkewT-LogP diagram showing the radiosonde data collected at PAFA at 1200 UTC on 8 January 2020 between the surface and the $600 \mathrm{mb}$ pressure level.

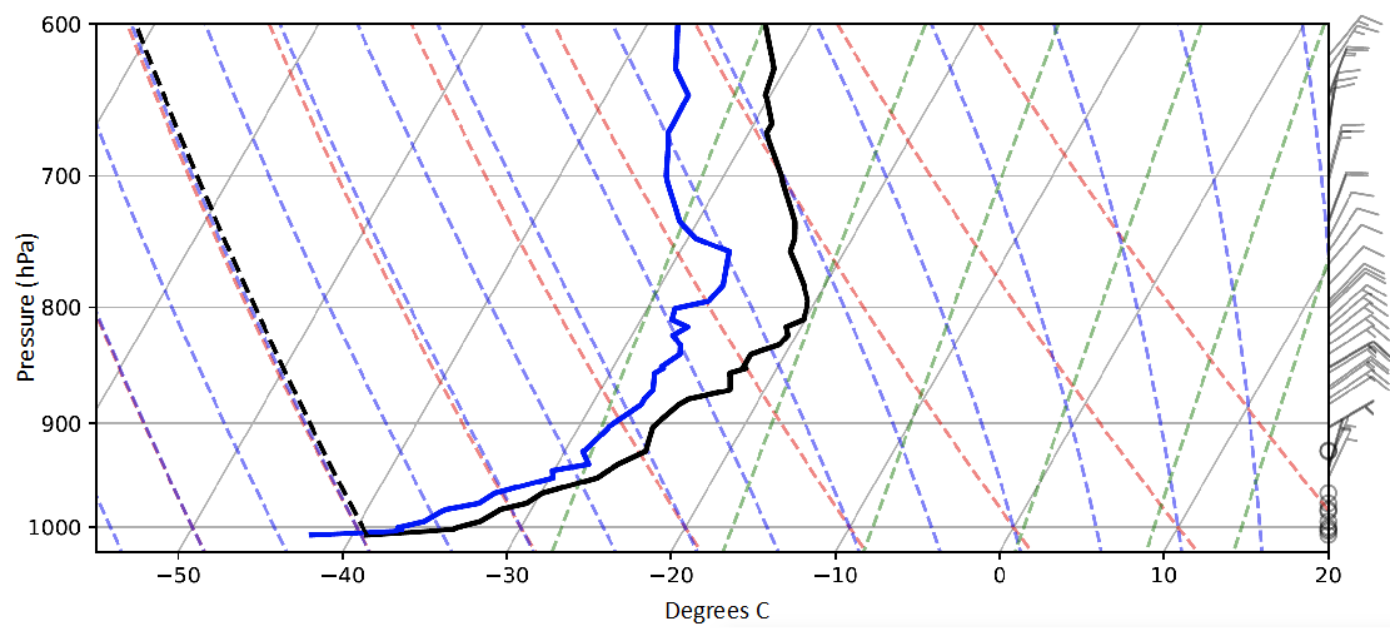

\subsection{Weather observation discussion}

The review of observational techniques and reported observational weather data indicates that the assumption that ice fog occurs in extreme cold events might not be valid. There remains the possibility of a heterogeneous environment where larger ice particles (e.g., diamond dust or precipitation) are the cause for obscuration (e.g., Kumai and O'Brien 1965; Schmitt et al. 2013; Kanji et al. 2017). To that point, the ASOS report of haze or mist introduces significant uncertainty as to the actual nature of the obscuring ice particles and as to whether very small ice fog particles are the primary, or dominant, obscurant. In addition, it has long been recognized that smoke from wood stoves and fireplaces used for heating or combustion products from automobiles also exist in the environment and could be incorrectly accounted for as haze or mist in the ASOS observations. Consequently, the ASOS observations provide supporting, but not conclusive, evidence for research findings regarding the existing of ice fog. There remains a requirement to gather additional information about the cold environment's ice particles. These observations need to be gathered at various locations and vertical levels to account for the heterogeneity of the Fairbanks region, as tower and transect observations show (e.g., Benson 1965; Magee et al. 1999). Therefore, temperature, humidity and ice particle structure observations need to be gathered for extended periods to provide a solid foundation for developing an understanding of the occurrence and evolution of ice fog in the Fairbanks region.

Regarding radiosonde data, there are only 13 release stations for the state of Alaska; and these radiosonde releases provides data approximately 
every 30 seconds to 1 minute for a flight lasting in excess of several hours. The wide spacing between stations and the long duration of the flights means that the spatiotemporal resolution of the collected data is insufficient for use as the only source of vertical atmospheric data describing ice fog events. That is, the radiosonde data might provide only a few data points on a horizontal map every 12 hours from which a description of the SBI as well as the humidity profile can be obtained. Additional sources of vertical temperature, humidity, and wind data need to be acquired to better characterize the low-level environment near the power generation plumes observed during extreme cold weather events.

To address the gaps in observational data, this study is collecting a set of colocated ice particle and weather observations in the Fairbanks region. CRREL scientists are collecting these observations to address both the uncertainty of ice particle structures during periods of extreme cold and the other spatiotemporal questions regarding ice fog formation near power generation at Fort Wainwright. The following chapter will provide information regarding the installed observational equipment, and subsequent chapters will offer details regarding the analysis of the observations. 


\section{Instrumentation and Data Collection}

\subsection{Instrumentation and field locations}

An observation network deployed on the Fort Wainwright Main Installation to investigate adverse weather conditions consists of two R.P.O. ATTEX MTP-5 meteorological temperature profilers (Models MTP-5HE and MTP-5PE, fabricated by R.P.O. ATTEX, Dolgoprudny, Russia) and two Axis Q3708-PVE network panoramic cameras (Axis Communications, Lund, Sweden). The temperature profilers measure air temperature up to $1000 \mathrm{~m}$ vertically, and the Axis cameras capture $180^{\circ}$ high-resolution panoramas. The panoramic cameras and the MTP- $5 \mathrm{HE}$ temperature profiler are deployed on the roof of CRREL's Alaska Regional Office, building 4070 on Fort Wainwright, at $64^{\circ} 49.81^{\prime} \mathrm{N}, 147^{\circ} 39.98^{\prime} \mathrm{W}$; the MTP-5PE instrument is deployed at the Ladd Army Airfield at $64^{\circ} 50.20^{\prime} \mathrm{N}, 147^{\circ} 35.76^{\prime} \mathrm{W}$ (Figure 5). Several factors have influenced the choice of deployment locations: minimal obstructions between instruments, the ability to view areas of interest (e.g., the heat and power plant and the airfield), access to an electrical power supply, and restrictions associated with military installations (e.g., camera restrictions at Army airfields).

The panoramic Axis cameras at building 4070 are oriented north, at a heading of $345^{\circ}$, towards Birch Hill and east, at a heading of $90^{\circ}$, facing the power plant. Both cameras are mounted $10 \mathrm{~m}$ AGL on $5 \mathrm{~cm}$ diameter galvanized metal poles anchored to the roof railing (Figure $6 a$ and $6 b$ ). Camera power and communication is supplied from inside the building via a single Ethernet cable. The MTP-5HE temperature profiler positioned at building 4070 is installed at an elevation of $9.5 \mathrm{~m}$ above the surface level with its base secured to the roof railing. The instrument sensor is oriented towards the northeast with a heading of $59^{\circ}$ and overlooks an open field and roadway with forested land beyond the reported instrument range (Figure 6c). The MTP-5HE is powered by a $120 \mathrm{~V}$ outlet, and an RS323 cable is used to transfer data to a computer inside building 4070 that records and archives observations.

The MTP-5PE temperature profiler deployed at Ladd Army Airfield is 1.5 $\mathrm{m}$ AGL with the sensor oriented towards the west with a heading of $275^{\circ}$ so that it overlooks the Ladd Army Airfield (Figure 6d). Power to the instrument is via an on-site $120 \mathrm{~V}$ outlet that was installed to support equipment previously located at this location. The computer controlling 
the instrument is housed at the Ladd Army Airfield Base Operations, building 1558, and is accessed by U.S. Air Force Staff Weather Officers in real time aiding the daily activities of pilots and airfield personnel. A pair of Freewave FGR3 $900 \mathrm{MHz}$ radios provide secure wireless communication between the instrument and the controlling computer inside building 1558.

Figure 5. Research area map: The Fort Wainwright main installation is located at the east end of Fairbanks city and $18 \mathrm{~km}$ northwest of the town of North Pole. The directional orientation of the observational instruments and the line of sight are displayed as dotted line arrows.

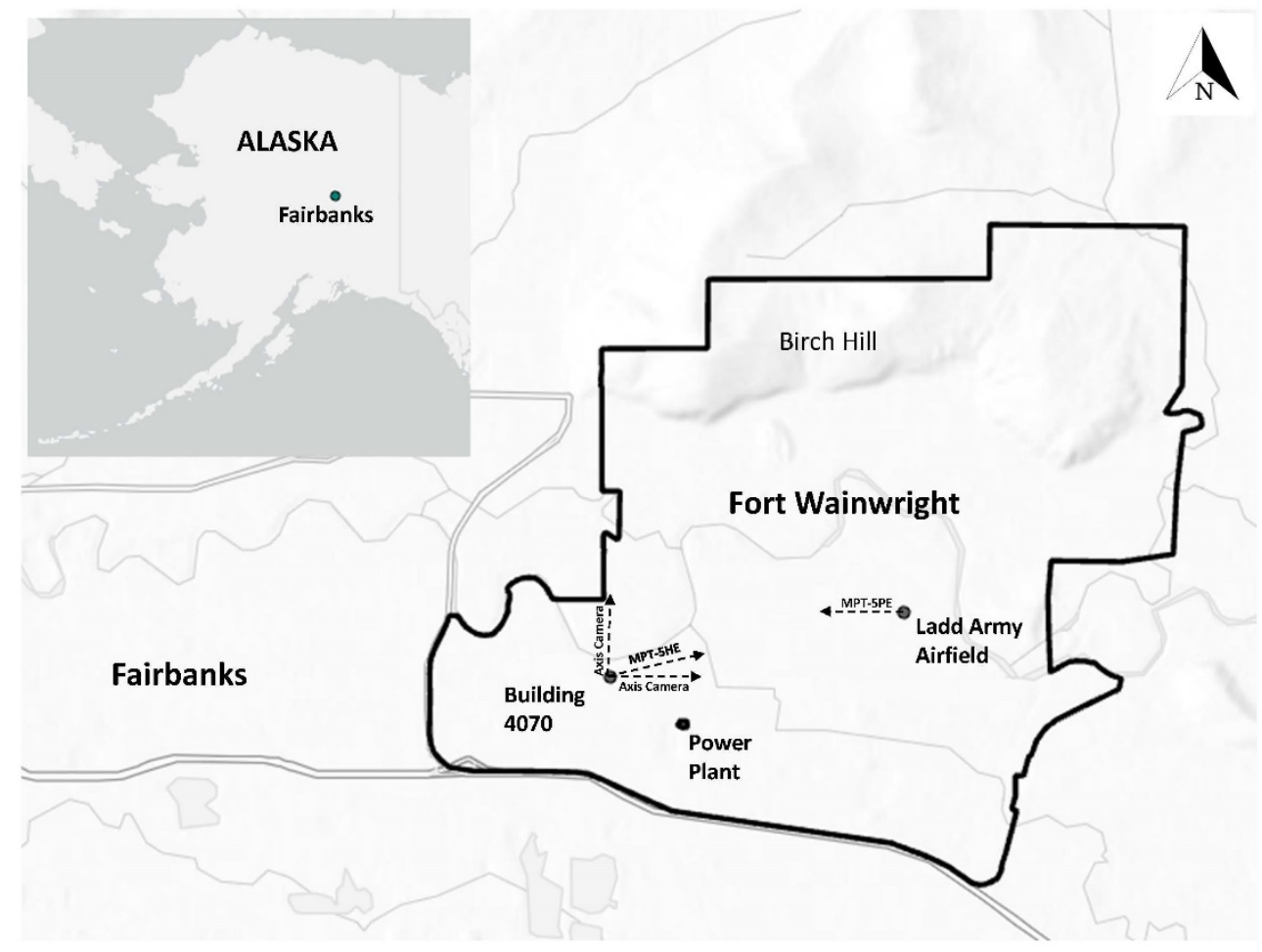


Figure 6. Instrumentation field deployment: (a) north-facing Axis camera, (b) east-facing Axis camera, (c) MTP-5HE, and (d) MTP-5PE.

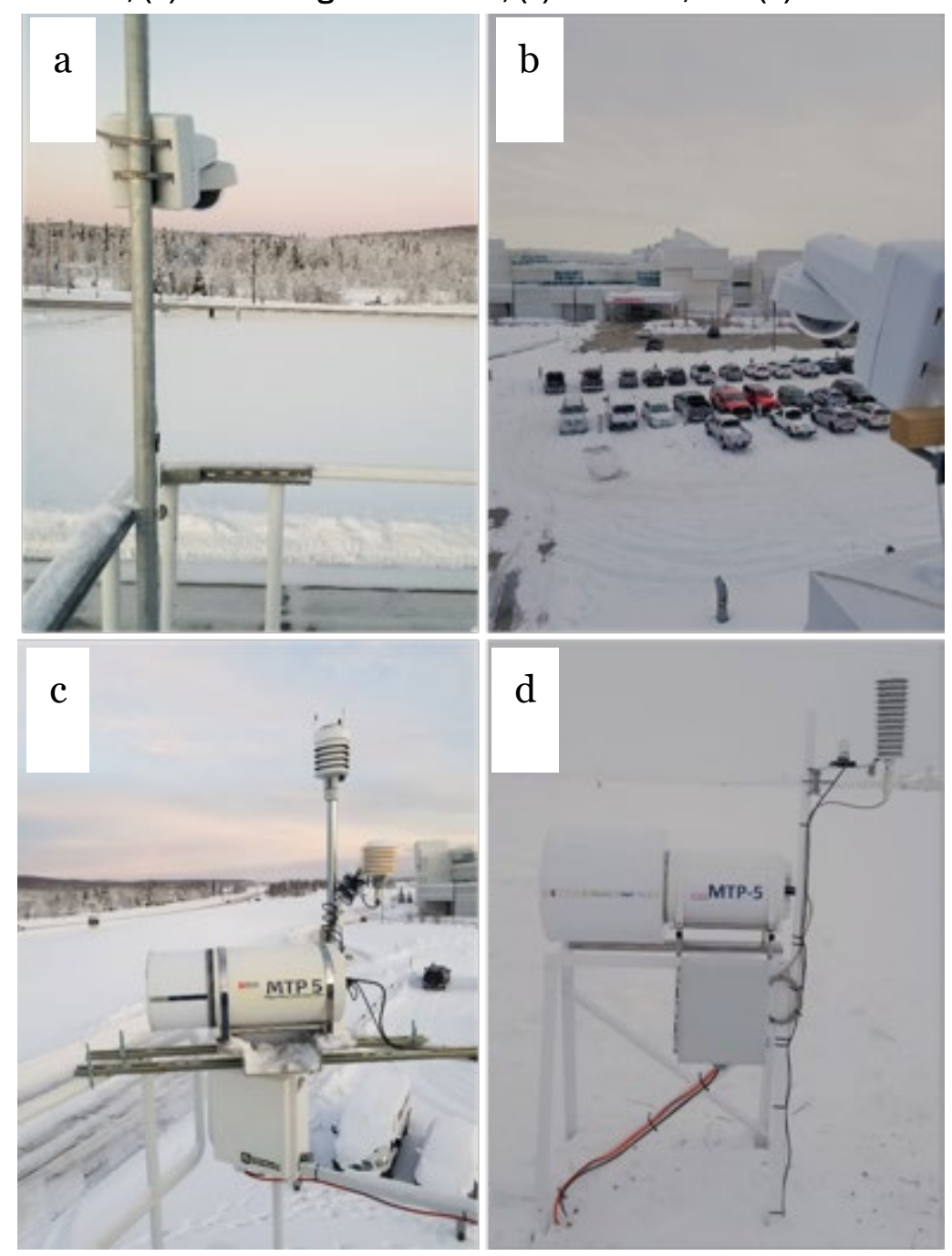

Both of the MTP- 5 instruments use an angular-scanning single-channel passive microwave to measure the thermal radiation (brightness temperature) of the atmosphere at the center of the molecular oxygen absorption line, $14 \mathrm{~dB} / \mathrm{km}$ at a $5 \mathrm{~mm}$ wavelength. Thermal radiance is measured at different zenith angles from $0^{\circ}$ to $90^{\circ}$ by the mechanical rotation of the receiver and antenna. That the instrument generates an area measurement is important to understanding not only where each MTP-5 should be located but also that the recorded instrument observations are actually measurements of emissions produced by the atmosphere across an area. The reason the MTP observations are for an area is that the atmosphere is a very week source of microwave radiation, and an unobstructed view of at least $1000 \mathrm{~m}$ is required to produce a measure of the average thermal radiance at each scanning angle. A thermometer mounted next to the 
instrument is an additional data source when calibrating the MTP- 5 instrumentation. The MTP- 5 instruments are operated using the R.P.O ATTEX MPT-5 Windows-compatible software, which provides instrument control; measurement quality assurance; sensor calibration; and data collection, storage, and visualization. The primary functional difference between the MTP-5HE and the MTP-5PE sensors is the measurement resolution at lower elevations; Table 2 provides the technical specifications for the MTP-5 models.

Table 2. MPT-5HE and MPT-5PE meteorological temperature profiler parameters provided by the manufacturer (RPO ATTEX 2013).

\begin{tabular}{|c|c|c|}
\hline Parameter & MPT-5HE & MPT-5PE \\
\hline Range & $0-1000 \mathrm{~m}$ & $0-1000 \mathrm{~m}$ \\
\hline Displayed height interval & $\begin{array}{l}25 \mathrm{~m} \text { from } 0 \text { to } 100 \mathrm{~m} \\
50 \mathrm{~m} \text { from } 100 \text { to } 1000 \mathrm{~m}\end{array}$ & $\begin{array}{l}10 \mathrm{~m} \text { from } 0 \text { to } 100 \mathrm{~m} \\
25 \mathrm{~m} \text { from } 100 \text { to } 200 \mathrm{~m} \\
50 \mathrm{~m} \text { from } 200 \text { to } 1000 \mathrm{~m}\end{array}$ \\
\hline $\begin{array}{l}\text { Minimum measurement } \\
\text { interval }\end{array}$ & $180 \mathrm{~s}$ & $180 \mathrm{~s}$ \\
\hline $\begin{array}{l}\text { Temperature accuracy, } \\
\text { root-mean-square error }\end{array}$ & $\begin{array}{l}0.25^{\circ} \mathrm{C} \text { from } 0 \text { to } 50 \mathrm{~m} \\
0.25^{\circ} \mathrm{C}-0.9^{\circ} \mathrm{C} \text { from } 50 \text { to } 600 \mathrm{~m} \\
0.9^{\circ} \mathrm{C}-1.2^{\circ} \mathrm{C} \text { from } 600 \text { to } 1000 \mathrm{~m}\end{array}$ & $\begin{array}{l}0.25^{\circ} \mathrm{C} \text { from } 0 \text { to } 50 \mathrm{~m} \\
0.25-0.9^{\circ} \mathrm{C} \text { from } 50 \text { to } 600 \mathrm{~m} \\
0.9-1.2^{\circ} \mathrm{C} \text { from } 600 \text { to } 1000 \mathrm{~m}\end{array}$ \\
\hline Receiver sensitivity & $0.07^{\circ}$ & $0.07^{\circ}$ \\
\hline Altitude accuracy & $25 \%$ & $25 \%$ \\
\hline Operation conditions & $-40^{\circ} \mathrm{C}$ to $50^{\circ} \mathrm{C}$ & $-80^{\circ} \mathrm{C}$ to $45^{\circ} \mathrm{C}$ \\
\hline Scanning angles & 9 & 11 \\
\hline
\end{tabular}

The MTP-5HE and MTP-5PE sensors measure vertical air temperature up to $1000 \mathrm{~m}$ every 5 minutes. The MTP- $5 \mathrm{HE}$ provides a measured temperature profile with data every $25 \mathrm{~m}$ from o to $100 \mathrm{~m}$ AGL and then every $50 \mathrm{~m}$ from 100 to $1000 \mathrm{~m}$ AGL. The MTP-5PE has a higher spatial resolution; data is provided at $10 \mathrm{~m}$ increments from o to $100 \mathrm{~m} \mathrm{AGL}$, every $25 \mathrm{~m}$ from 100 to $200 \mathrm{~m}$ AGL, and every $50 \mathrm{~m}$ from 200 to $1000 \mathrm{~m}$ AGL. One of the main field deployment requirements was for a $1000 \mathrm{~m}$ unobstructed horizontal and vertical field of view for the microwave sensor. This is possible near the airfield with minimal effort (the sensor is oriented towards the west, viewing across an open area near the airfield). However, at the building 4070 site, the nearby topography, vegetation, and infrastructure restricts the possible instrument orientation; Figure $6 c$ shows the optimal orientation at this location. 
The Axis Q370 8-PVE Network Panoramic Cameras are a fixed dome with three 5-megapixel-resolution sensors that capture a $180^{\circ}$ panoramic view. Table 3 presents detailed camera specifications.

Table 3. Axis Q370 8-PVE specifications provided by the manufacturer (Axis Communications 2020).

\begin{tabular}{|l|l|}
\hline Image sensor & $\begin{array}{l}\text { Three } 1 / 1.8 \text { in. progressive scan CMOS (complementary metal } \\
\text { oxide semiconductor) }\end{array}$ \\
\hline Lens & Three lenses, fixed focus, $5.0 \mathrm{~mm}, \mathrm{~F} 2.8$ \\
\hline Minimum illumination & $\begin{array}{l}\text { Color: } 0.3 \text { lux, F2.8 } \\
\text { Black and White: } 0.06 \text { lux, F2.8 }\end{array}$ \\
\hline Shutter time & $1 / 71500 \mathrm{~s}$ to $1 \mathrm{~s}$ \\
\hline $\begin{array}{l}\text { Camera angle } \\
\text { adjustment }\end{array}$ & $\begin{array}{l}\text { Pan } \pm 180^{\circ} \\
\text { Tilt } 18^{\circ} \text { to } 75^{\circ}\end{array}$ \\
\hline Frame rate & Three 5 megapixels, up to $16 / 20$ frames per second \\
\hline Memory & 2.5 GB, $512 \mathrm{MB}$ Flash. \\
\hline Power (over Ethernet) & $18.3 \mathrm{~W}$ typical, $25.5 \mathrm{~W}$ max \\
\hline Media storage & Network-attached storage \\
\hline Operation conditions & $-40^{\circ} \mathrm{C}$ to $55^{\circ} \mathrm{C}$ \\
\hline
\end{tabular}

Air temperature data at 2 and $10 \mathrm{~m}$ above the surface is measured at a separate site near building 4070 by using a CS215 Campbell Scientific air temperature and relative humidity probe (air temperature accuracy: $\pm 0.4^{\circ} \mathrm{C}$ from $5^{\circ} \mathrm{C}$ to $40^{\circ} \mathrm{C}$ ) and a Vaisala WXT530 weather transmitter (air temperature accuracy: $\pm 0.3^{\circ} \mathrm{C}$ at $20^{\circ} \mathrm{C}$ ), respectively.

During the 2020 winter season, ice particle measurements were made with the University of Hartfordshire (United Kingdom) particle phase discriminator (PPD; Vochezer et al. 2016). The instrument was on loan from the Karlsruhe Institute of Technology. The PPD is a ground or laboratory version of the Small Ice Detector 3 (Schmitt et al. 2016). The PPD's principle of operation entails drawing ice particles into the instrument where they pass through a visible-band laser beam. The ice particle scatters light from the laser, and this scattered light is imaged with a charge-coupled device (CCD) array. The CCD produces an image of the forward-scattered light, which is then used to identify characteristics of the particle. Each particle is examined individually through the use of a trigger signal, which is generated when an ice particle is in the sensing area; but the CCD camera is limited to its operational capability of recording images at a maximum rate 
of 30 frames per second. All trigger signals are counted and recorded so the subset of imaged particles can be scaled by the total number of triggers to determine an accurate representation of the total number of near-surface ice particles present near the collection device. The PPD is most effec-

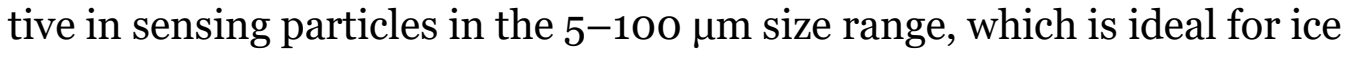
fog observations (Schmitt et al. 2013).

From the forward scattering patterns, it is possible to determine a lot of particle characteristics. Particle size is generally a function of total scattered light. Particle shape can also be readily identified for select common shapes. Of particular interest for ice fog studies, particle roughness can be easily measured using the scattering patterns. Particle roughness can be a function of particle nuclei (Schnaiter et al. 2016).

\subsection{Data collection and observations}

Data from all instruments and cameras were collected from 17 December 2019 to 31 March 2020 at the building 4070 site and from 4 February 2020 to 31 March 2020 at the Ladd Army Airfield site. The Axis cameras were programed to capture one image per sensor (three sensors per camera) every 10 minutes and to store the images on the local computer. UAF python-based software was used to combine these simultaneously captured images to create a wide-angle, $180^{\circ}$ panoramic view. Figure 7 provides a sample panoramic image from the two Axis cameras. The northfacing camera was installed with the center sensor oriented towards Birch Hill, the left sensor angled north-northwest towards Fairbanks, and the right sensor shifted north-northeast toward Ladd Army Airfield (Figure 7a). The east-facing camera was installed with the center sensor oriented towards the Fort Wainwright main power generation facility, the left sensor views more towards the east-northeast in the direction of Birch Hill, and the right sensor angled east-southeast towards the edge of the parking facilities and an open area that was once the cooling ponds (Figure $7 b$ ). From the east camera perspective, the power plant is located behind the hospital (the large building in the center of Figure $7 b$ ). The panoramic image in Figure $7 a$ does not have a flat surface despite best attempts to align the images. Future efforts will address this, but the two panoramic images can still be used to study the environmental conditions. 
Figure 7. Sample panoramas from (a) the north-facing Axis camera and (b) the east-facing Axis camera.

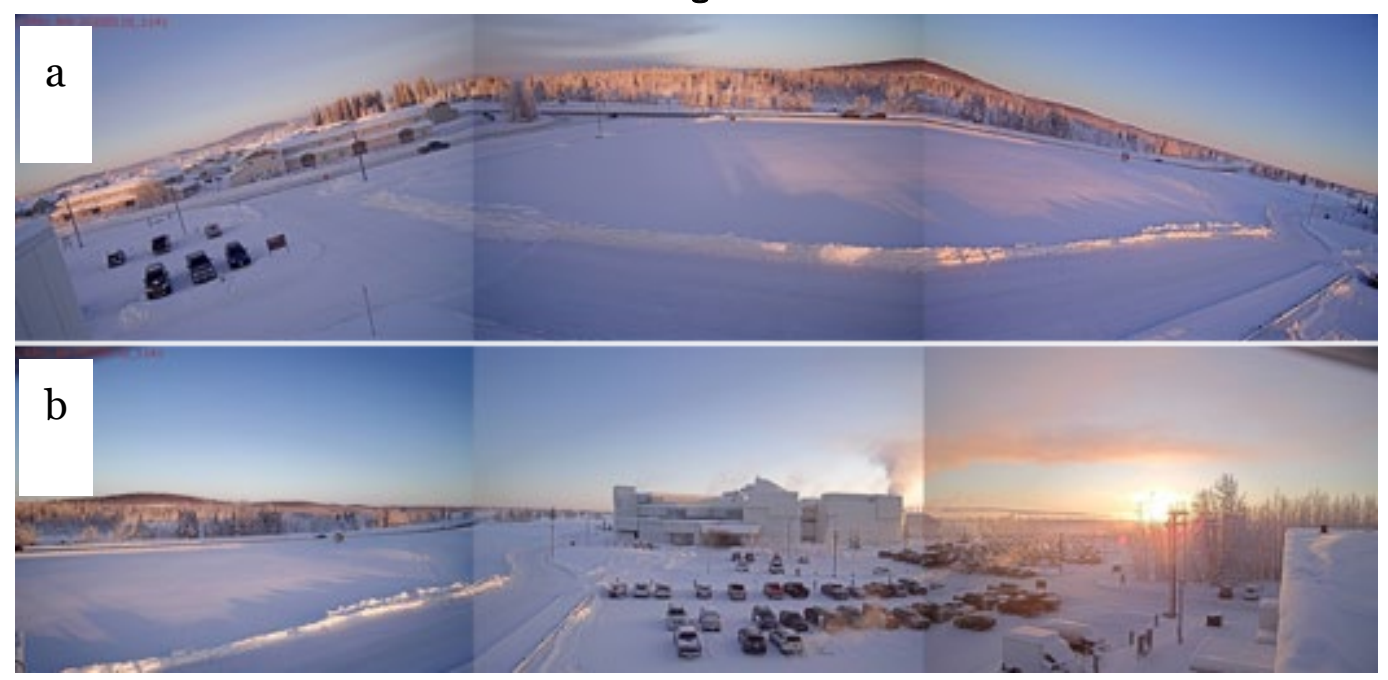

To highlight the relatively high spatial and temporal resolution of the MTP-5PE observations, Figure 8 plots the temperature profiles collected from 1 through 30 January 2020 and compares them to the lowest $1000 \mathrm{~m}$ of the National Weather Service radiosonde sound data collected twice daily at Fairbanks International Airport. The comparison does not factor in the elevation differences between the MTP unit being located on top of building 4070 (approximately $150 \mathrm{~m}$ mean sea level) and that of Fairbanks International Airport located at $134 \mathrm{~m}$ mean sea level. In addition, previous research efforts have recognized and studied in detail the development of an urban heat island in the Fairbanks region during the cold season (e.g., Bowling and Benson 1978; Magee et al. 1999). This urban heat island and other factors can account for a temperature difference of several degrees Celsius between the two locations, but the purpose of this comparison is to focus on the similar evolution of warming and cooling of atmospheric layers in both sounding observations and the MTP systems. Further, the MTP systems provide a view of the near-surface temperature profile with much greater detail and more frequently (5-minute interval and $25 \mathrm{~m}$ vertical spacing for the MTP-5HE) than the twice-daily National Weather Service atmospheric soundings; but it does so by observing a large area, thereby effectively removing small-scale horizontal temperature fluctuations. 
Figure 8. Microwave temperature profiler MTP-5PE (a) versus Fairbanks International Airport soundings (b) for January 2020.

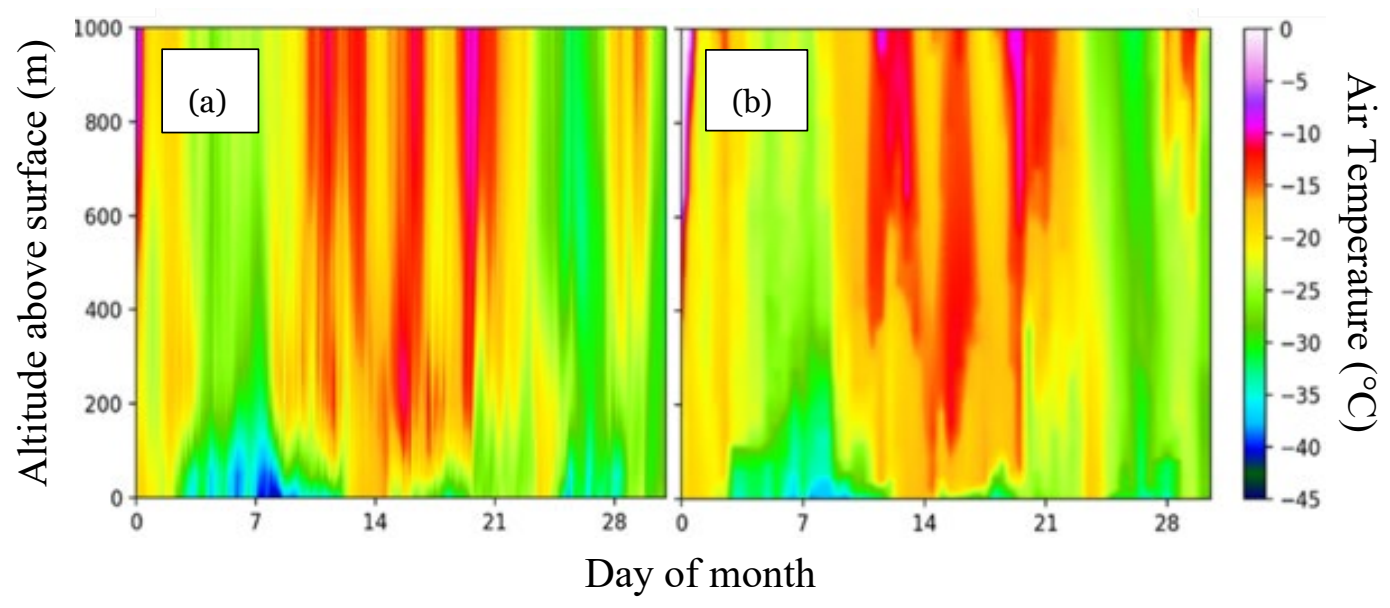

The higher vertical and temporal resolution of the MTP-5PE introduces the ability to capture subhourly low-level temperature fluctuations during colder days around 6 to 10 January 2020. That the data from MTP-5PE is able to graphically reveal these lower-level temperature changes and highlight subhourly variability suggests a potential utility of the dataset in evaluating observations and investigating local phenomena. For example, the MTP observations can be compared with the local observations from building 4070 as well as those of Ladd Army Airfield to provide a quality check of the observed temperature magnitude. Comparing the timing and depth of temperature changes could provide some additional insight into the mesoscale variations associated with terrain, motor vehicle activities, and power and heat generation in the Fort Wainwright area. One possible investigation stems from Benson (1965), who used a network of multiple weather towers and several vehicle transects in the proximity of Fort Wainwright and observed a significant amount of temperature variability across the local region not only at the surface but also upwards to $150 \mathrm{~m}$ AGL. These observations by Benson (1965) led to several findings, including the suggestion that the fluctuations had a frequency and magnitude similar to those that would be produced by wave-like motions analogous to a seiche. The MTP data could provide additional support to the existence of a seiche and aid in understanding the near-surface cloud-layer evolution during ice fog events.

During the 2020 winter season, the Particle Phase Detector-2000 (PPD2K; Vochezer et al. 2016) was operated on 12 days sampling fog particles. The PPD2K measures the forward scattered light as particles pass through a laser beam. The scattered light can be used to determine both 
particle size and shape characteristics. As different types of ice nuclei can lead to different ice-crystal growth, these data can be used to understand the population of ice nuclei in the atmosphere. The PPD2K was operated at building 4070 at Fort Wainwright with its inlet at the ground level. Figure 9 shows sample scattering patterns and an example particle size distribution. Between January and February 2020, approximately 1,000,000 particle scattering images were collected. Preliminary analysis suggests that at least $95 \%$ of atmospheric particles were solid ice; liquid droplets were extremely rare. Particle sizes ranged from 7 to $50 \mu \mathrm{m}$ with substantial variability based on weather conditions at the time of collection.

Figure 9. Example scattering patterns and size distribution using data collected January and February 2020 from the PPD2K.

\section{Particle Phase Discriminator PPD2K}

Measures forward scattered light from fog particles

Growing particles show crisp edges to scattered light.
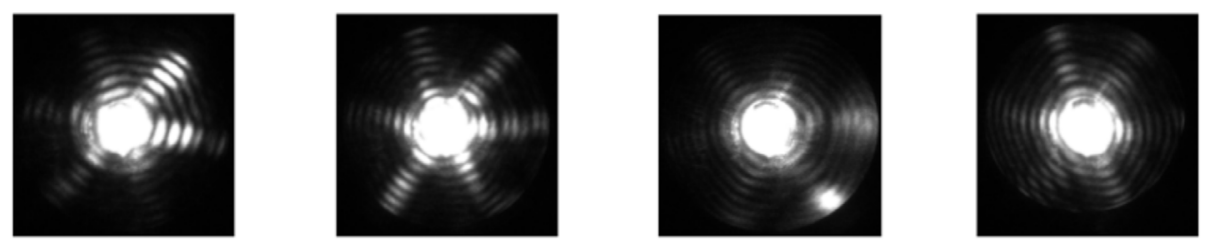

Melting or sublimating particles show rounded edges to scattered light.
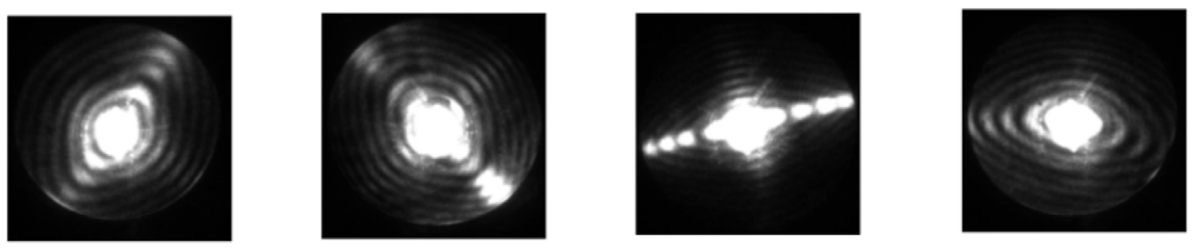

Sample particle size distribution Particles generally smaller than $\mathbf{2 0}$ microns

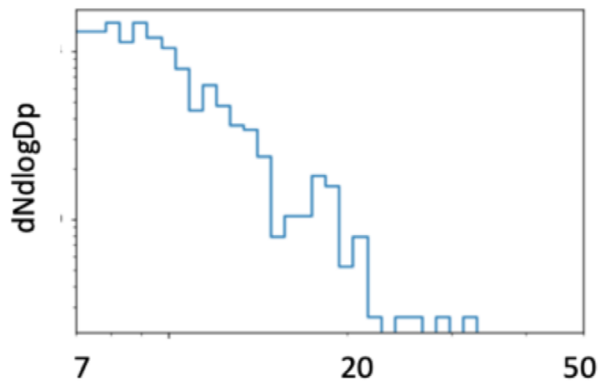

Preliminary results show that $>95 \%$ of particles are ice and that liquid (spherical) particles are extremely rare. 


\section{Imagery and Spatiotemporal Analysis}

The high-resolution panoramic images were generated from photographs captured by the two Axis cameras deployed at building 4070 for the cold season starting December 2019. This study used these images, along with the high-resolution temperature profiles collected by the MTP-5HE at building 4070, to identify and record the formation, maturation, and recovery of ice fog events on Fort Wainwright. The analysis in this study was constrained to only the periods when the surface air temperature reported by the MTP- $5 \mathrm{HE}$ was $-30^{\circ} \mathrm{C}$ or colder. This threshold was selected because the American Meteorological Society defines this temperature threshold at which ice fog conditions consistently develop. The individual panoramas are subjectively analyzed for the visible presence of ice fog events and assigned an intensity value from o to $3: 0$, no ice fog detected; 1, ice fog identified; 2, light ice fog; and 3, heavy ice fog. Appendix A provides examples of products from this classification method. The event intensity values were recorded along with the corresponding photograph time stamp, air temperature, and ice fog source if identifiable (e.g., a visible plume or cloud extending from the surface near the power plant). Future analysis will examine products from the subjective analysis to determine the formation, location, and evolution of ice fog conditions at Fort Wainwright and near the power generation facilities.

To account for the seasonal variation in the shortwave radiation effect on the ice fog events, the dataset is grouped into two categories: winter, 17 December 2019 to 12 January 2020, and early spring, 13 January 2020 to $31 \mathrm{March} 2020$. The ice fog events were investigated through the whole temperature range from $-30^{\circ} \mathrm{C}$ to $-40.9^{\circ} \mathrm{C}$ (lowest air temperature recorded) in the winter months and from $-30^{\circ} \mathrm{C}$ to $-38.1^{\circ} \mathrm{C}$ (lowest air temperature recorded) in the early spring months at $2^{\circ} \mathrm{C}$ intervals to better understand the temperature effects on ice fog events.

One limitation to the analytical process is the restriction to a single view angle. During the cold season starting December 2020, an additional set of images will be generated using a camera on Birch Hill. The ability to triangulate location and edge evolution will provide the ability to validate any moisture plume location and to better estimate the speed of its lateral movement. 
Another limitation is that the panoramic images from building 4070 do not have a vantage point that ensures that, for all distances beyond the foreground, the obscuring cloud layer is actually in contact with the surface (ice fog) rather than a layer suspended just above the surface layer. Therefore, this study assumes that, since the moisture emissions were from near the surface, the lateral extent of the moisture plume is included in the areas of ice fog. 


\section{Results and Discussion}

From 17 December 2019 to 31 March 2020, there were several periods of various length with $-30^{\circ} \mathrm{C}$ or lower air temperatures. The longest periods were during December 2019 and January 2020 (Figure 10). A noticeable increase in the diurnal air temperature variation started in early February 2020 , with temperature swings as high as $22.6^{\circ} \mathrm{C}$ within an approximate 9-hour interval, as the surface solar radiation input increased along with total daylight hours. A total of 3273 records for the east camera and 3102 records for the north camera datasets were gathered during that collection period.

Figure 10. Air temperature at building 4070, 17 December 2019 to 31 March 2020. The coefficient of determination value between the $2 \mathrm{~m}$ and $10 \mathrm{~m}$ air temperature datasets was 0.9884 , which indicates there is little variation between the two datasets.

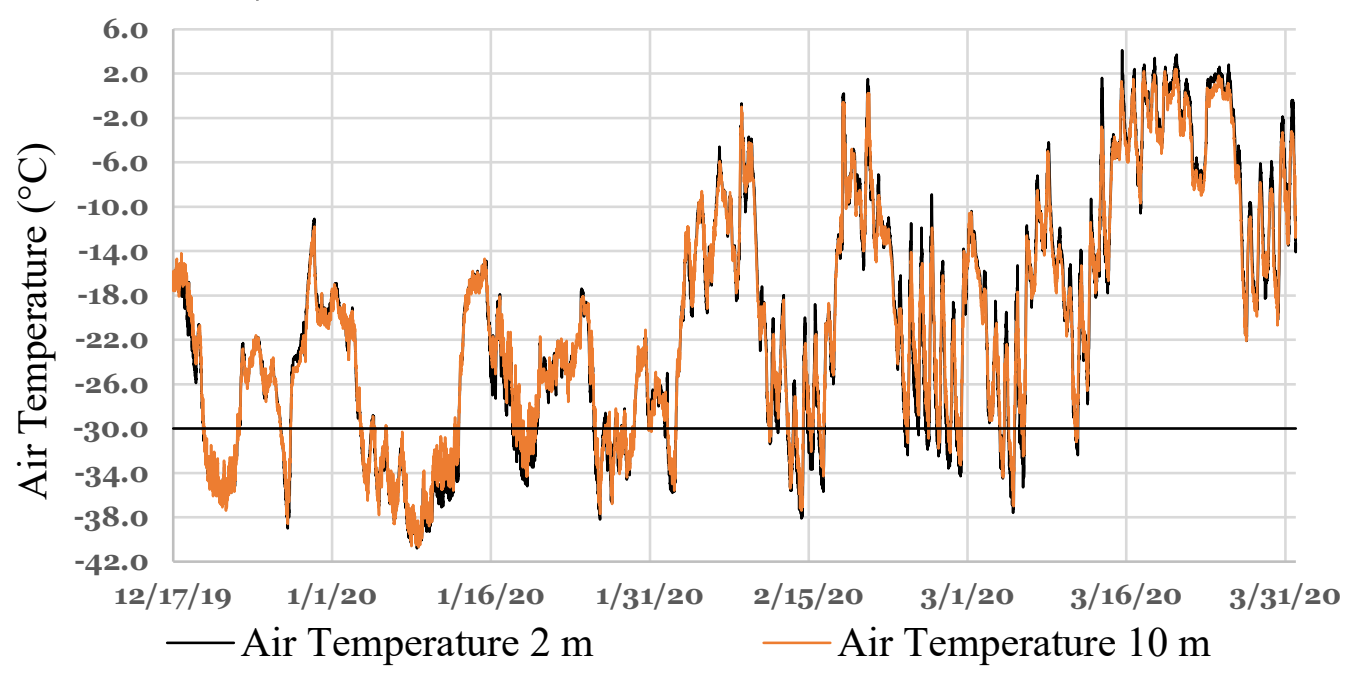

During the winter when air temperatures were $-30^{\circ} \mathrm{C}$ or lower, $33 \%$ of the images collected from the east camera and $20 \%$ of the images collected from the north camera showed ice fog events. These occurrences decreased in the early spring months where $11 \%$ of the east camera images and $5 \%$ of the north camera images showed ice fog events.

Figure 11 reveals that most of the ice fog events in the winter months occurred when surface air temperatures were below $-33^{\circ} \mathrm{C}$ in both the east and north datasets. The data collected for the east dataset reveals that $51 \%$ of the ice fog events occurred at air temperatures below $-36^{\circ} \mathrm{C}$ while the north dataset indicates that ice fog events were present $63 \%$ of the time for the same air temperature range. All of the heavy ice fog events, when the 
most significant reduction in visibility occurs, were captured by the north dataset and occurred when the observed air temperature was $-40^{\circ} \mathrm{C}$ or lower while $95 \%$ of the heavy ice fog events in the east dataset occurred under the same temperature conditions.

Figure 11. Ice fog records for the (a) east and $(b)$ north panoramic images obtained between 17 December 2019 and 12 January 2020.

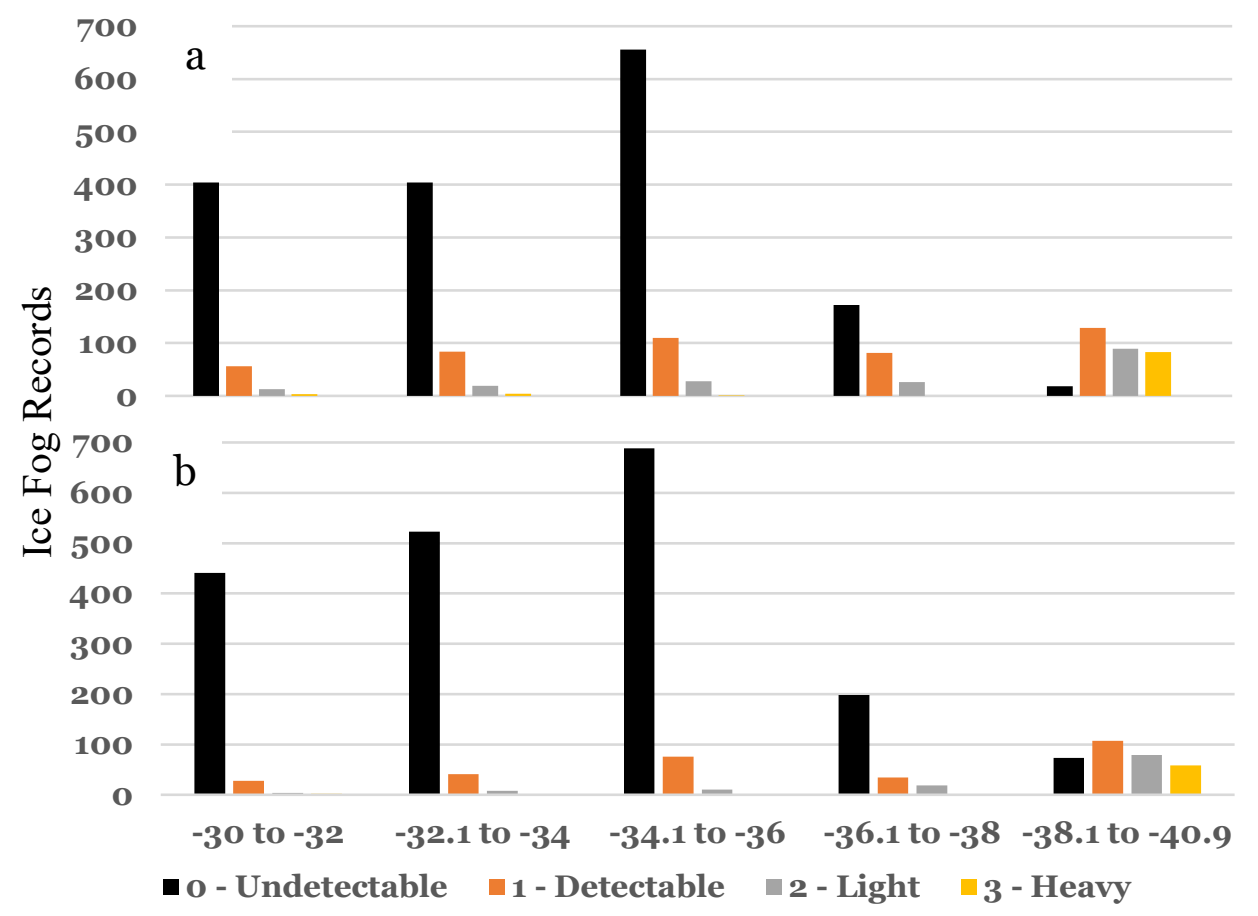

Temperature range $\left({ }^{\circ} \mathrm{C}\right)$

A similar analysis of the spring months dataset revealed similar findings (Figure 12); $36 \%$ of ice fog events in the east dataset and $55 \%$ of the events in the north dataset occurred when the temperature was $-36^{\circ} \mathrm{C}$ or lower. No heavy ice fog events were observed during the spring months. The vast majority, $84 \%$ in the east dataset and $97 \%$ in the west dataset, of recorded ice fog events were subjectively classified as detectable.

The duration of ice fog events as captured by the panoramas varies from fewer than 10 minutes to 1340 minutes (0.9 days) in the east dataset and less than 10 minutes to 1100 minutes (o.8 days) in the north dataset. As expected, the length of ice fog events was closely related to the duration and consistency of the air temperatures remaining lower than $-34^{\circ} \mathrm{C}$. The month of January had the most consistency between the two panoramas; ice fog was classified as present for 6950 minutes (4.8 days) in the east dataset and 4460 minutes (3.1 days) in the north dataset. February followed 
with the second most occurrences of ice fog with 440 minutes (approximately 0.3 days) detected in the east dataset and 240 minutes (approximately 0.2 days) detected in the north dataset.

Figure 12. Ice fog records for the $(a)$ east and $(b)$ north panoramas, 13 January 2020 to 31 March 2020.

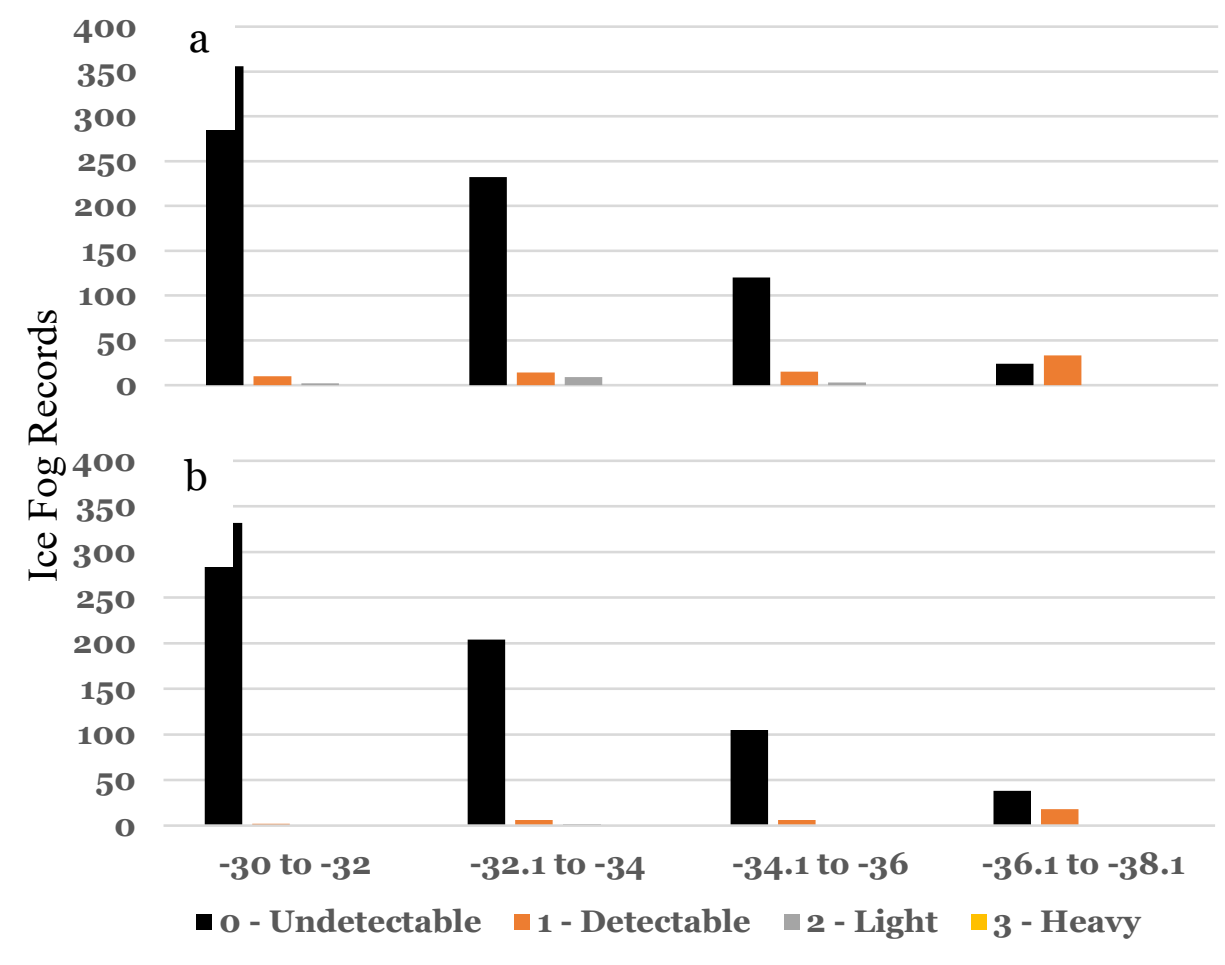

Temperature range $\left({ }^{\circ} \mathrm{C}\right)$

The main power generation facility on Fort Wainwright is identified in the photographs (e.g., Figure $7 \mathrm{~b}$ ) as a likely source of ice fog generation in $74 \%$ of the east panoramas during the winter and in $49 \%$ during the early spring. The north panoramas could not be used for this purpose as the camera pointed away from the power plant due to Ladd Army Airfield regulations. Overall, there were $38 \%$ fewer ice fog records in the north panoramas than in the east panoramas. The difference between the north and east panoramas can be explained in part by the longer field of view in the east images but also due to the power plant's absence from the north camera's field of view. The difference in ice fog records between the two datasets also suggests that the ice fog events are mostly constrained by the low-level moisture emissions source in addition to the wind magnitude and direction. 
The temperature profile data from the two MTP- 5 profilers at building 4070 (Figure 13a) and Ladd Army Airfield (Figure 13b) for 29 February 2020 reveal a light ice fog event followed by a shallow temperature inversion. The observed ice fog started forming at 0541 AKST (Alaska Standard Time) when the air temperature lowered to $-34^{\circ} \mathrm{C}$ and recovered by 0611 AKST. The ice fog event was followed by a substantial warming during the day with ground-level air temperature reaching $-15.6^{\circ} \mathrm{C}$ at $1431 \mathrm{AKST}$. In general, the agreement between the two temperature profilers is good with minor differences possibly due to the different locations or instrument uncertainty. The Ladd Army Airfield profiler, with its higher resolution near the surface and being mounted closer to the terrain surface was better able to characterize the end of the inversion as compared to the building 4070 instrument.

Figure 13. Microwave temperature profiler MTP-5HE (a) and MTP-5PE (b) data for 29 February 2020.

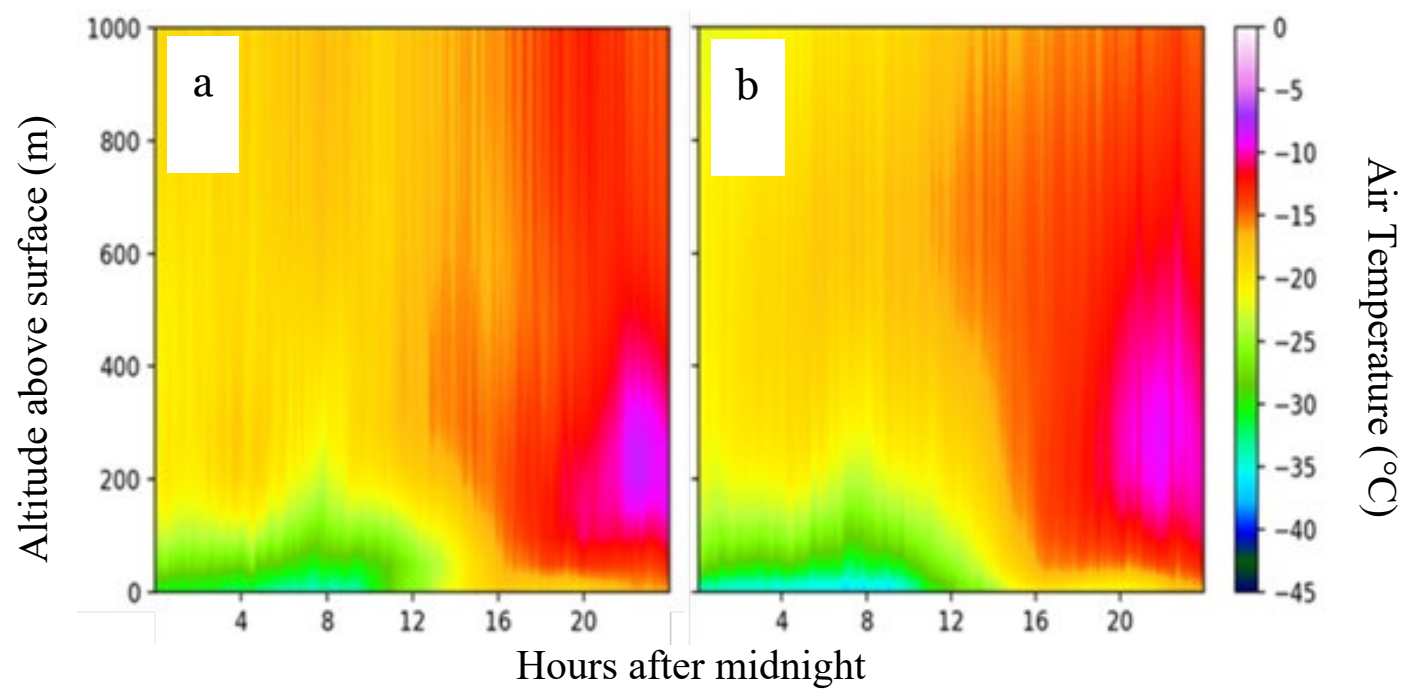

The ice fog event from 29 February is also captured in the east panoramas shown in Figure 14: (a) formation, $(b)$ maturation, and (c) recovery. Based on these images, there appears to be a moisture plume that propagates across Fort Wainwright from the power generation facility toward the camera located on building 4070. This movement of the plume from the local power plant towards the camera indicates that the power plant is the local moisture source for this ice fog event. However, image analysis requires caution. For example, the analysis assumes that moisture sources from power generation and heating nearby buildings do not affect the event. This assumption seems reasonable as there are only short and quickly dissipating plumes near other buildings in the images prior to and 
after the plume encompasses the camera location, but additional observations should be made as the plumes from heat and energy production are influenced by the local temperature and specific humidity.

The challenge of image analysis is to estimate the plume edge movement as the change in the closest obscured location is assumed to represent the horizontal wind. From these images, the plume appears to descend from the top of the inversion layer downward to the surface and thereafter diffuses across the local area. Also, the transition in ice fog phases, and likewise horizontal visibility, appears to be associated with changes in the wind direction between the surface and the top of the moisture plume (not only in magnitude across the layer but also from an easterly to westerly direction). A potential issue with this image analysis is the inability to triangulate the position of the moisture plume edge. Again, the uncertainty of the plume location and any settling of larger ice particles formed in the vicinity of the moisture plume necessitates a second set of panoramic images. The installation of an additional two Axis Q3708-PVE Network Panoramic Camera on Birch Hill during the spring of 2020 addresses this need. Additionally, a vertical wind profiler, or a weather station on Birch Hill, would be beneficial to aid in describing low-level horizontal winds that transport the plumes produced from heat and power generation.

With the future installation of an additional camera, the image analysis combined with the temperature profiling should be able to triangulate the location of the power generation moisture plume. The temperature profiler should aid with the vertical elevation of the moisture plume trapped by the overlying inversion. It may reveal vertical mixing and particle transport under the plume as a shallow layer of nearly uniform air temperature. Finally, capturing images of the ice fog particles would allow characterization of the ice particles size and shape evolution. This will provide insight as to whether precipitation is falling from the plume or if new ice particles are being generated near the surface. 
Figure 14. Ice fog event evolution on 29 February: (a) 0541 AKST, (b) 0601 AKST, and (c) 0651 AKST.

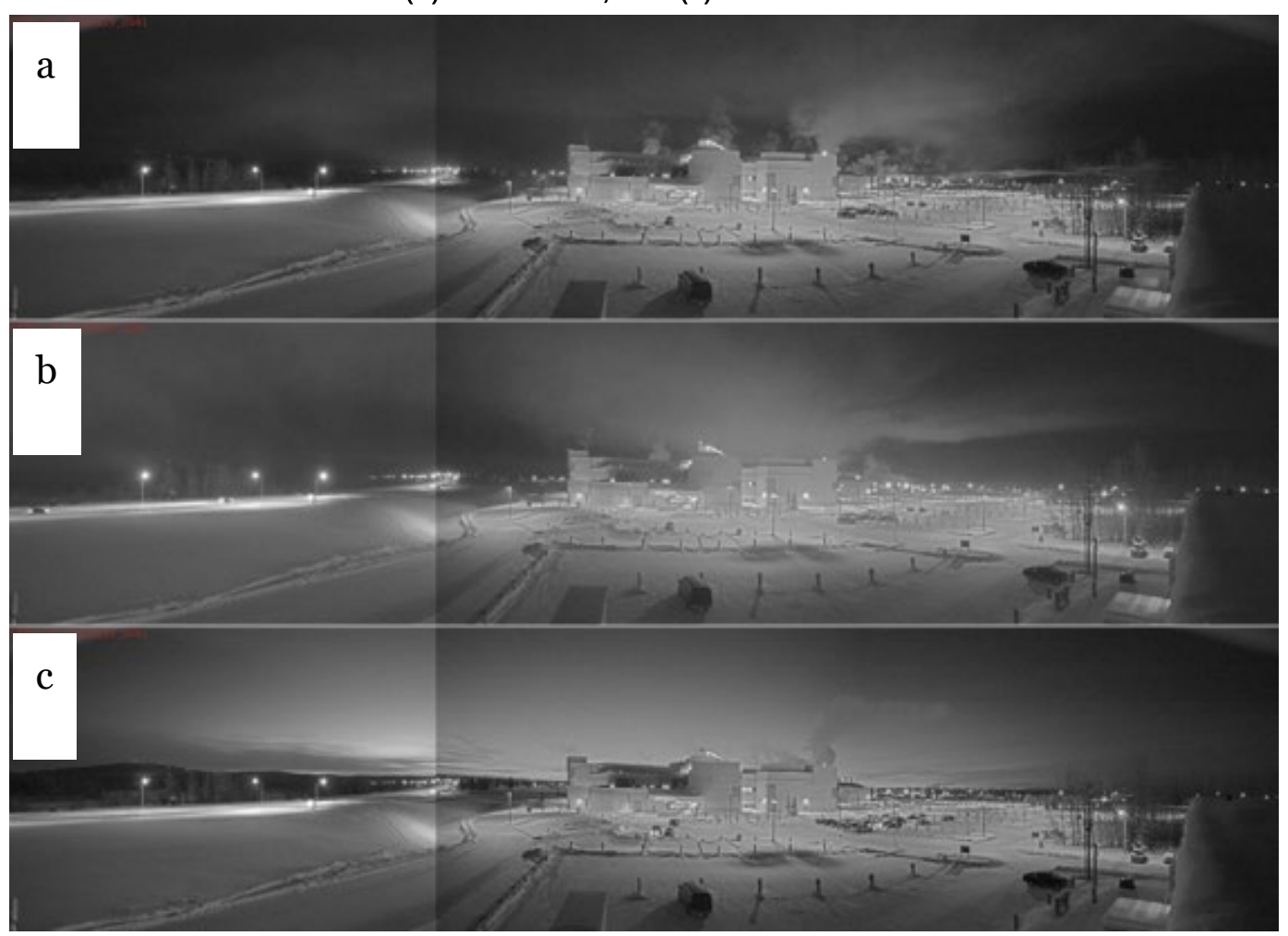




\section{Conclusions and Recommendations}

This ice fog monitoring effort focused on developing, implementing, and testing innovative methods for identifying and characterizing ice fog environmental conditions in the Fort Wainwright, Alaska, region. This report documents the observational equipment deployed and used in an ice fog research program conducted during the winter of December 2019 through March 2020. Included with the documentation of the instrumentation at Fort Wainwright are examples of the collected data and techniques used to investigate data with a focus towards identifying the means of formation and structure of ice particles and their migration. This information will be utilized in a separate numerical modeling study investigating ice fog in the Fairbanks, Alaska, region (e.g., Kim et al. 2014).

\subsection{Conclusions}

Several findings from this project can lead towards answering the questions raised in section 1.1. The initial analysis of ice fog events based on ASOS weather reports obtained at airports and communities across the Arctic demonstrates that these observational datasets can contain significant errors. These errors stem from the inability of the automated system's visibility algorithm to correctly classify ice fog events as well as uncertainty of the ice particle size and characteristics. The necessary knowledge about the environment to determine whether ice fog particles are present is obtained from measurement and characterization of the suspended ice particles by using devices such as the Particle Phase Detector. That an error in identifying ice fog exists in an environment suggests that the meteorological community's preference for using the criteria of surface air temperature lower than $-30^{\circ} \mathrm{C}$, calm winds ( 1 minute mean speed below $1 \mathrm{~m} / \mathrm{s}$ ), and reduced visibility for reporting ice fog is wrong and that findings based on those observations alone are based upon speculation. Investigative studies of ice fog require supporting evidence obtained through careful measurement not only of the meteorological state but also the number, structure, and evolution of the ice particles. Further, the ASOS visibility algorithm warrants enhancement for environments experiencing extremely low temperatures to generate reports that better reflect current surface weather conditions.

This study also reveals the utility of high-frequency, high-resolution temperature profile data. Previous investigations tended to characterize the 
evolution of ice fog based on hourly surface temperature observations and twice-daily atmospheric soundings. The findings from this study reveal the extremely shallow nature of the surface-based inversion and the rapid environmental evolution as the inversion erodes and ice fog dissipates. The simultaneous collections from MTP systems and panoramas have shown that ice fog events can occur at local scales within very short time periods (i.e., several hours) not fully captured by hourly weather observation reports. Further, a single hourly observation having a fortuitous occurrence of ice fog at the exact moment of observation fails to represent the true time and spatial scale of the event (i.e., aliasing). Questions remain regarding the frequency of these short-lived ice fog events, and an additional investigation would be necessary before characterizing these events and determining if there is a relationship between these short-lived events and forcing mechanisms, such as vehicle traffic and smaller-scale heat and power generation.

The findings from the study also reveal that ice fog does not always occur even though extremely low air temperatures and calm winds exist. The panoramas for select periods of time show that surface visibility near or greater than $16 \mathrm{~km}$ can occur when the ice fog threshold is met and a shallow cloud deck exists. In these situations, the meteorological criteria for ice fog has been satisfied, but weather observations fail to indicate the existence of ice fog through reduced visibility. Hence, applications of the meteorological criteria to nearby transportation arteries such as the Richardson Highway have significant uncertainty of environmental conditions with the potential for significant false alarm rates. Additional investigations into ice fog conditions along major transportation corridors need to be conducted to better understand the local influences on ice fog to ensure accurate advisories of ice fog.

This investigation documents the methods to install and operate observational equipment in a harsh and complex environment, the means undertaken to ensure data access, and evidence supporting its successful operation through preliminary findings. The data collection also serves to enhance current understanding of ice fog events in the Fort Wainwright region.

The data in this collection lead to several preliminary conclusions: 
- Preliminary analysis of the PPD2K data gathered during ice fog events suggests that at least $95 \%$ of atmospheric particles were solid ice with liquid droplets being extremely rare; particle sizes generally ranged from 7 to $50 \mu \mathrm{m}$ with substantial variability based on weather conditions at the time of collection.

- Preliminary analysis of the panoramic images collected from 17 December 2019 to 31 March 2020 suggests that up to $63 \%$ of the ice fog events occurred at $-36^{\circ} \mathrm{C}$ or lower, $97 \%$ of the ice fog events were in the detectable category, and $100 \%$ of the heavy ice fog events occurred at $-40^{\circ} \mathrm{C}$ or lower.

- The local power plant was a likely source of ice fog generation $74 \%$ of the time despite the removal of the cooling ponds discussed in previous studies.

This project successfully installed and tested observational instruments during extremely low temperatures (air temperatures as low as $-40.9^{\circ} \mathrm{C}$ ), and the observations obtained from the equipment begin to address the scientific questions outlined in the study objectives. That is, the observations address questions regarding where ice fog develops on Fort Wainwright and how the ice fog evolves over time. Despite having identified the power generation facility as the mechanism of ice fog, supporting findings from previous studies, there still remains a need to collect more observations to quantify the mechanisms modulating ice fog event intensity and spatial extent. Such information will not only lead to improved forecasts of reduced visibility during ice fog events but also aid in improving safety on roadways and airfields in the Fairbanks, Alaska, region.

\subsection{Recommendations}

Further information is needed to gain a more holistic view of the local and regional meteorological conditions that promote ice fog formation. Ideally, observations of temperature profiles would also collect humidity and wind profile information. Some of these observations would occur near the moisture plume to provide validation of the observed plume location and movement as computed in the analysis effort. One location that has additional equipment being installed is the Birch Hill location where a set of panoramic images will be collected for the cold season beginning in December 2020. Also, if resources became available, additional temperature and wind profile observations should be added east of Fort Wainwright in the North Pole, Alaska, region. These observations would provide insight and deeper understanding of the near-surface environment at Fort 
Wainwright and how it could influence the ice fog formation near power generation facilities.

Collaboration with the broader scientific community would also be beneficial. For example, the Alaskan Layered Pollution and Chemical Analysis (ALPACA) field program is conducting observations in the Fort Wainwright region, focusing on the formation and transport of pollutants. This field program will gather weather observations and air chemistry measurements in the Fairbanks region. Further, there will be mobile laboratory observations near and downwind from major pollution sources such as North Pole, Alaska. These observations could supplement the investigations into power generation at Fort Wainwright by characterizing the upwind environment. Additional information from the ALPACA study regarding the observed air quality could be used in the investigation of ice particle structure and morphology, addressing questions about the potential relationship between environmental pollution (e.g., smoke from biomass burning) and the formation or evolution of ice particulates near Fort Wainwright. 


\section{References}

American Meteorological Society. 2012. "Ice Fog." Glossary of Meteorology. Last modified 25 April 2012. http://glossary.ametsoc.org/wiki/lce_fog.

Axis Communications. 2020. AXIS Q3708-PVE Network Camera. Datasheet. Lund, Sweden: Axis Communications.

https://www.axis.com/files/datasheet/ds_q3708pve_t10063091_en_2011.pdf.

Benson, C. S. 1965. Ice Fog: Low Temperature Air Pollution Defined with Fairbanks, Alaska as Type Locality. UAG R-173. College, Alaska: University of Alaska, Geophysical Institute. https://scholarworks.alaska.edu/handle/11122/3646.

—. 1970. "Ice fog." Weather 25:11-18. https://doi.org/10.1002/j.1477-8696.1970.tb03223.x.

Bilello, M. A. 1966. Survey of Arctic and Subarctic Temperature Inversions. Technical Report 161. Hanover, NH: U.S. Army Cold Regions Research and Engineering Laboratory.

Bourne, S. M., U. S. Bhatt, J. Zhang, and R. Thoman. 2010. "Surface-Based Temperature Inversions in Alaska from a Climate Perspective.” Atmospheric Research 95 (23): 353-366. https://doi.org/10.1016/j.atmosres.2009.09.013.

Bowling, S. A., and C. S. Benson. 1978. Study of the Subarctic Heat Island at Fairbanks, Alaska. EPA-600/4-78-027. Washington, DC: Environmental Protection Agency.

Bowling, S. A., T. Ohtake, and C. S. Benson. 1968. "Winter Pressure Systems and Ice Fog in Fairbanks, Alaska." Journal of Applied Meteorology 7 (6): 961-968. https://doi.org/10.1175/1520-0450(1968)007<0961:WPSAIF>2.0.C0;2.

Bradley, R. S., F. T. Keimeg, and H. F. Diaz. 1992. "Climatology of Surface-Based Inversions in the North American Arctic.” Journal of Geophysical Research 97 (D14): 15699-15712. https://doi.org/10.1029/92JD01451.

Bush, N., U. Ebel, H. Kraus, and E. Schaller. 1982. "The Structure of the Subpolar Inversion-Capped ABL." Archives for Meteorology, Geophysics, and Bioclimatology, Series A 33:1-18. https://doi.org/10.1007/BF02257738.

Chemel, C., S. Staquet, and Y. Largeron. 2009. "Generation of Internal Gravity Waves by a Katabatic Wind in an Idealized Alpine Valley." Meteorology and Atmospheric Physics 103:187-194. https://doi.org/10.1007/s00703-009-0349-4.

Curry, J. A., W. B. Rossow, D. Randall, and J. L. Schramm. 1996. "Overview of Arctic Cloud and Radiation Characteristics." Journal of Climate 9:1731-1764. https://doi.org/10.1175/1520-0442(1996)009<1731:00ACAR>2.0.C0;2.

Girard, E., and J.-P. Blanchet. 2001a. "Microphysical Parameterization of Arctic Diamond Dust, Ice Fog, and Thin Stratus for Climate Models." Journal of Atmospheric Science 58 (10): 1181-1198. https://doi.org/10.1175/15200469(2001)058<1181:MPOADD>2.0.C0;2. 
—. 2001b. "Simulation of Arctic Diamond Dust, Ice Fog, and Thin Stratus Using an Explicit Aerosol-Cloud-Radiation Model.” Journal of Atmospheric Science 59:1199-1221. https://doi.org/10.1175/1520-0469(2001)058<1199:SOADDI>2.0.C0;2.

Gotaas, Y., and C. S. Benson. 1965. "The Effect of Suspended Ice Crystals on Radiative Cooling." Journal of Applied Meteorology 4 (4): 446-453. https://doi.org/10.1175/1520-0450(1965)004<0446:TEOSIC>2.0.C0;2.

Gultepe, I., and A. Heymsfield. 2016. "Introduction Ice Fog, Ice Clouds, and Remote Sensing." Pure and Applied Geophysics 173:2977-2982. https://doi.org/10.1007/s00024-016-1380-2.

Gultepe, I., A. J. Heymsfield, M. Gallagher, L. Ickes, and D. Baumgardner. 2017. "Ice Fog: The Current State of Knowledge and Future Challenges." Meteorological Monographs 58:4.1-4.24. https://doi.org/10.1175/AMSMONOGRAPHS-D-17-0002.1.

Gultepe, I., T. Kuhn, M. Pavolonis, C. Calvert, J. Gurka, A. J., HeymsfIeld, P. S. K. Liu, B. Zhou, R. Ware, B. Ferrier, J. Milbrandt, and B. Bernstein. 2014. "Ice Fog in Arctic during FRAM-IF Project: Aviation and Nowcasting Applications." Bulletin of the American Meteorological Society 95:211-226.

Gultepe, I., B. Zhou, J. Milbrandt, A. Bott, Y. Li, A. J. Heymsfield, B. Ferrier, R. Ware, M. Pavolonis, T. Kuhn, J. Gurka, J., P. Liu, and J. Cermak. 2015. "A Review on Ice Fog Measurements and Modeling." Atmospheric Research 151:2-19. http://dx.doi.org/10.1016/j.atmosres.2014.04.014.

Gultepe, I., R. Sharman, P. D. Williams, B. Zhou, G. Ellrod, P. Minnis, S. Trier, S. Griffin, Seong. S. Yum, B. Gharabaghi, W. Feltz, M. Temimi, Z. Pu, L. N. Storer, P. Kneringer, M. J. Weston, H. Chuang, L. Thobois, A. P. Dimri, S. J. Dietz, G. B. França, M. V. Almeida, and F. L. Albquerque Neto. 2019. "A Review of High Impact Weather for Aviation Meteorology." Pure and Applied Geophysics 176:1869-1921. https://doi.org/10.1007/s00024-019-02168-6.

Hartmann, B., and G. Wendler. 2005. "Climatology of the Winter Surface Temperature Inversion in Fairbanks, Alaska.” In Proceedings of the 8th Conference on Polar Meteorology and Oceanography and the 16th Symposium on Global Change and Climate Variations, 10-13 January 2005, San Diego, CA. Boston, MA: American Meteorological Society. https://ams.confex.com/ams/Annual2005/webprogram/Paper84504.html.

Kahl, J. D., M. C. Serreze, and R. C. Schnell. 1992. "Tropospheric Low-Level Temperature Inversions in the Canadian Arctic." Atmosphere-Ocean 30 (4): 511e529.

Kanji, Z. A., L. A. Ladino, H. Wex, Y. Boose, M. Burkert-Kohn, D. J. Cziczo, and M. Krämer. 2017. "Overview of ice nucleating particles. Ice Formation and Evolution in Clouds and Precipitation: Measurement and Modeling Challenges." Meteorological Monographs 58 (1): 1.1-1.33.

Kim, C., M. Stuefer, C. Schmitt, A. Heymsfield, and G. Thompson. 2014. "Numerical Modeling of Ice Fog in Interior Alaska Using the Weather Research and Forecasting Model." Pure and Applied Geophysics 171:1963-1982. https://doi.org/10.1007/s00024-013-0766-7. 
Kumai, M., and H. O’Brien. 1965. A Study of Ice Fog and Ice Fog Nuclei at Fairbanks, Alaska, Part II. Research Report 150. Hanover, NH: U.S. Army Cold Regions Research and Engineering Laboratory. https://apps.dtic.mil/dtic/tr/fulltext/u2/676811.pdf.

Magee, N., J. Curtis, and G. Wendler. 1999. "The Urban Head Island Effect at Fairbanks, Alaska." Theoretical and Applied Climatology 64:39-47. https://doi.org/10.1007/s007040050109.

Malingowski, J., D. Atkinson, J. Fochesatto, J. Cherry, and E. Stevens. 2014. “An Observational Study of Radiation Temperature Inversions in Fairbanks, Alaska." Polar Science 8 (1): 24-39. https://doi.org/10.1016/j.polar.2014.01.002.

Mayfield, J. A., and G. J. Fochesatto. 2013. "The Layered Structure of the Winter Atmospheric Boundary Layer in the Interior of Alaska." Journal of Applied Meteorology and Climatology 52 (4): 953-973. https://doi.org/10.1175/JAMC-D-12$\underline{01.1}$.

NOAA (National Oceanic and Atmospheric Administration), Department of Defense, Federal Aviation Administration, and U.S. Navy. 1998. Automated Surface Observing System (ASOS) User's Guide. Silver Spring, MD: National Oceanic and Atmospheric Administration. https://www.weather.gov/media/asos/aum-toc.pdf.

Ohtake, T. 1970. Studies on Ice Fog. UAG R-211. College, Alaska: University of Alaska, Geophysical Institute.

Pepin, N. C., M. K. Schaefer, and L. D. Riddy. 2009. "Quantification of the Cold Air Pool in Kevo Valley, Finnish Lapland.” Weather 64 (3): 60-67. https://doi.org/10.1002/wea.260.

Porteous, A., and G. Wallis. 1970. "A Contribution Towards the Reduction of Ice Fog Caused by Humid Stack Gases at Alaskan Power Stations.” Atmospheric Environment 4 (1): 21-32.

RPO ATTEX. 2013. “Temperature Profilers MTP-5.” RPO ATTEX. http://attex.net/EN/mtp5.php.

Schmitt, C. G., M. Stuefer, A. J. Heymsfield, and C. K. Kim. 2013. “The Microphysical Properties of Ice Fog Measured in Urban Environments of Interior Alaska." Journal of Geophysical Research Atmospheres 118 (19): 11,136-11,147. https://doi.org/10.1002/igrd.50822.

Schmitt, C. G., M. Schnaiter, A. J. Heymsfield, P. Yang, E. Hirst and A. Bansemer. 2016. "The Microphysical Properties of Small Ice Particles Measured by the Small Ice Detector-3 Probe during the MACPEX Field Campaign." Journal of Atmospheric Sciences 73 (12): 4775-4791.

Schnaiter, M., E Järvinen, P. Vochezer, A. Abdelmonem, R. Wagner, O. Jourdan, G. Mioche, V. Shcherbakov, C. G. Schmitt, U. Tricoli, Z. Ulanowski, and A. Heymsfield. 2016. "Cloud Chamber Experiments on the Origin of Ice Crystal Complexity in Cirrus Clouds.” Atmospheric Chemistry Physics 16 (8):5091-5110. https://doi.org/10.5194/acp-16-5091-2016. 
Shulski, M., and G. Wendler. 2007. The Climate of Alaska. Fairbanks, AK: University of Alaska Press.

Stull, R. B. 1988. An Introduction to Boundary Layer Meteorology. Boston: Kluwer Academic Publishers.

Tran, H. N. Q., and N. Molders. 2011. "Investigations on Meteorological Conditions for Elevated $\mathrm{PM}_{2.5}$ in Fairbanks, Alaska." Atmospheric Research 99 (1): 39-49. https://doi.org/10.1016/j.atmosres.2010.08.028.

Turner, J. K., J. Gyakum, and S.M. Milrad, 2013. "A Thermodynamic Analysis of an Intense North American Arctic Air Mass.” Monthly Weather Review 141 (1): 166181. https://doi.org/10.1175/MWR-D-12-00176.1.

Vochezer, P., E. Jearvinen, R. Wagner, P. Kupiszewski, T. Leisner, and M. Schnaiter. 2016. "In Situ Characterization of Mixed Phase Clouds Using the Small Ice Detector and the Particle Phase Discriminator." Atmospheric Measurement Techniques 9:159-177. https://doi.org/10.5194/amt-9-159-2016.

Walker, K. E., and W. Brunner. 1982. Suppression of Ice Fog from the Fort Wainwright, Alaska, Cooling Pond. Special Report 82-22. Hanover, NH: U.S. Army Cold Regions Research and Engineering Laboratory.

Wexler, H. 1936. "Cooling in the Lower Atmosphere and Structure of Polar Continental Air." Monthly Weather Review 64 (4): 122-136. https://doi.org/10.1175/15200493(1936)64<122:CITLAA>2.0.C0;2.

—. 1941. "Observations of Nocturnal Radiation at Fairbanks, Alaska and Fargo, N. Dak." Monthly Weather Review: Supplement 46.

University of Wyoming. 2019. “Atmospheric Soundings.” University of Wyoming, College of Engineering. Accessed 28 December 2020. http://weather.uwyo.edu/upperair/sounding.html. 


\section{Appendix A: Ice Fog Classification Examples}

The panoramic images captured with the east- and north-facing cameras mounted on building 4070 were visually inspected for the presence of ice fog. An intensity value from o to 3 was assigned to each image: 0 , no ice fog detected at ground level; 1 , ice fog detected at ground level in part of the panorama; 2, light ice fog detected at ground level throughout the panorama; and 3, heavy ice fog detected at ground level throughout the panorama. Examples of each are showed for the east panoramas in Figure A-1 and the north panoramas in Figure A-2.

Figure A-1. An ice fog classification example for the east panoramas (8 January 2020): (a) 0, no ice fog detected; (b) 1, ice fog detected; (c) 2, light ice fog; and ( $d$ ) 3, heavy ice fog. For perspective, the hospital building (large building in the center of the image) is located $120 \mathrm{~m}$ from the camera.

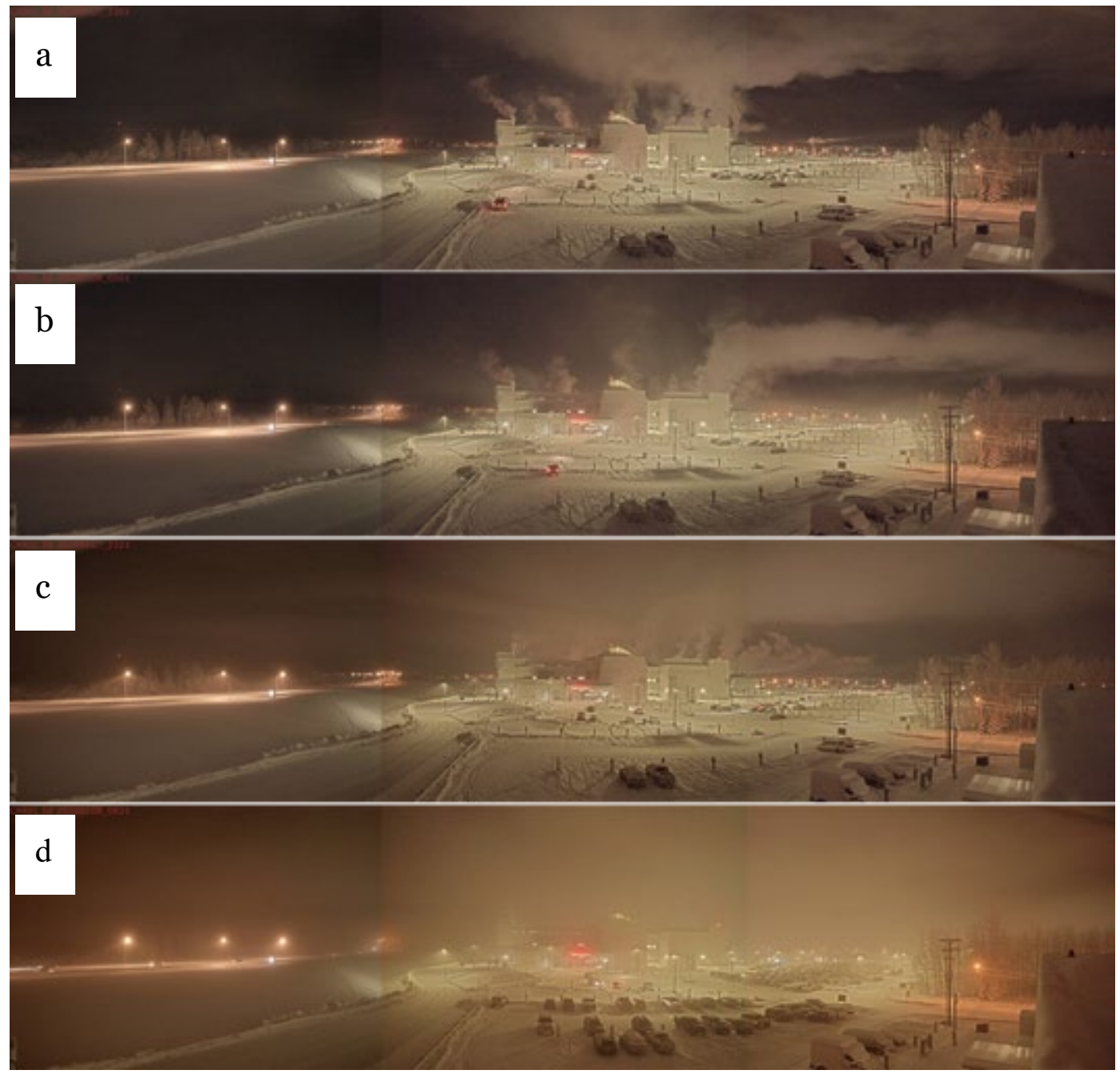


Figure A-2. An ice fog classification example for the east panoramas (8 January 2020): (a) 0, no ice fog detected; (b) 1, ice fog detected; (c) 2, light ice fog; and ( $d$ ) 3, heavy ice fog. For perspective, the traffic lights located in the center left of the images are $120 \mathrm{~m}$ from the camera.

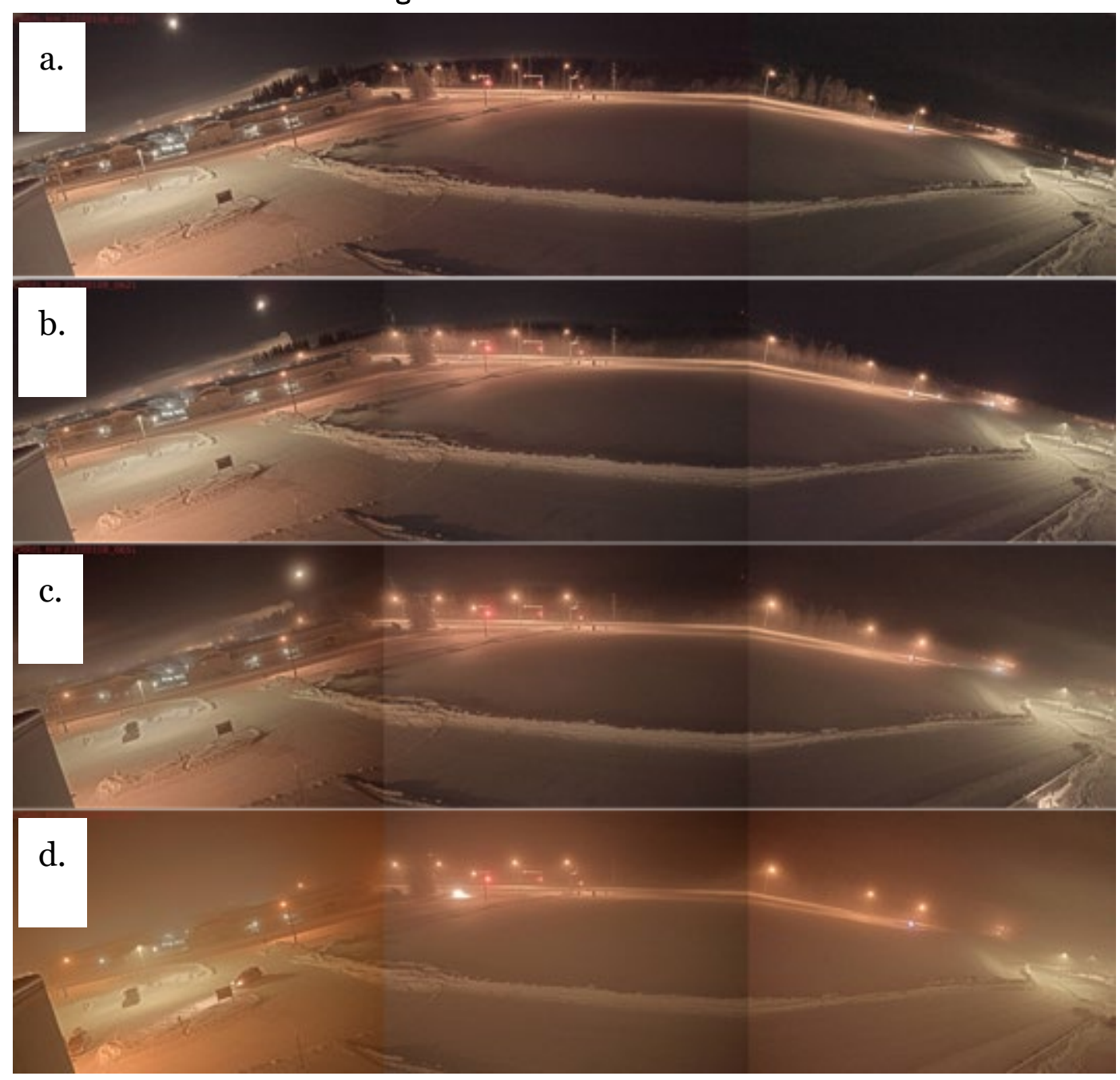




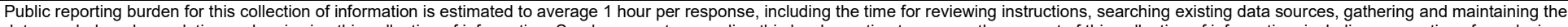

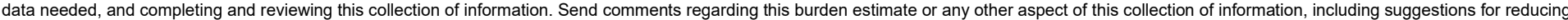

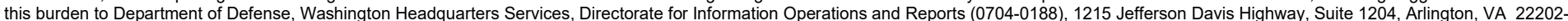

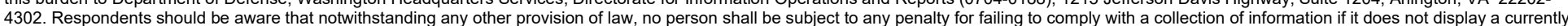

4302. Respondents should be aware that notwithstanding any other provision of law, no person shall
valid OMB control number. PLEASE DO NOT RETURN YOUR FORM TO THE ABOVE ADDRESS.
1. REPORT DATE (DD-MM-YYYY)
2. REPORT TYPE
Technical Report / Final

3. DATES COVERED (From - To)

4. TITLE AND SUBTITLE

5a. CONTRACT NUMBER

Ice Fog Monitoring Near Fairbanks, AK

\section{5b. GRANT NUMBER}

5c. PROGRAM ELEMENT

633734

\section{AUTHOR(S)}

Dragos A. Vas, Steven E. Peckham, Carl G. Schmitt,

Martin Stuefer, Ross G. Burgener, and Telayna E. Wong

5d. PROJECT NUMBER

TI1

5e. TASK NUMBER

5f. WORK UNIT NUMBER

\section{PERFORMING ORGANIZATION NAME(S) AND} ADDRESS(ES)

U.S. Army Engineer Research and Development Center (ERDC) Cold Regions Research and Engineering Laboratory (CRREL)

72 Lyme Road

Hanover, NH 03755-1290

\section{SPONSORING / MONITORING AGENCY NAME(S) AND ADDRESS(ES)}

Assistant Secretary of the Army for Acquisitions, Logistics, and Technology

103 Army Pentagon

Washington, DC 20314-1000

University of Alaska Fairbanks

Geophysical Institute

2156 Koyukuk Dr.

Fairbanks, AK 99775
8. PERFORMING ORGANIZATION REPORT NUMBER

ERDC/CRREL TR-21-2

10. SPONSOR/MONITOR'S ACRONYM(S)

11. SPONSOR/MONITOR'S REPORT NUMBER(S)

\section{DISTRIBUTION / AVAILABILITY STATEMENT}

Approved for public release; distribution is unlimited.

\section{SUPPLEMENTARY NOTES}

Funding was provided under PE 633734, Project TI1, "Secure and Resilient Power Generation in Cold Regions Environments"

\section{ABSTRACT}

Ice fog events, which occur during the Arctic winter, result in greatly decreased visibility and can lead to an increase of ice on roadways, aircraft, and airfields. The Fairbanks area is known for ice fog conditions, and previous studies have shown these events to be associated with moisture released from local power generation.

Despite the identified originating mechanism of ice fog, there remains a need to quantify the environmental conditions controlling its origination, intensity, and spatial extent. This investigation focused on developing innovative methods of identifying and characterizing the environmental conditions that lead to ice fog formation near Fort Wainwright, Alaska. Preliminary data collected from December 2019 to March 2020 suggest that ice fog events occurred with temperatures below $-34^{\circ} \mathrm{C}$, up to $74 \%$ of the time ice fog emanated from the power generation facility, and at least $95 \%$ of ice particles during ice fog events were solid droxtals with diameters ranging from 7 to $50 \mu \mathrm{m}$.

This report documents the need for frequent and detailed observations of the meteorological conditions in combination with photographic and ice particle observations. Datasets from these observations capture the environmental complexity and the impacts from energy generation in extremely cold weather conditions.

\section{SUBJECT TERMS}

Cold regions, Ice fog, Ice--Particles, Fort Wainwright (Alaska)

\section{SECURITY CLASSIFICATION OF:}

\section{a. REPORT}

Unclassified

\section{b. ABSTRACT}

Unclassified

\section{c. THIS PAGE}

Unclassified

\section{LIMITATION OF ABSTRACT}

SAR
18. NUMBER OF PAGES

57 19a. NAME OF RESPONSIBLE PERSON

19b. TELEPHONE NUMBER

(include area code) 